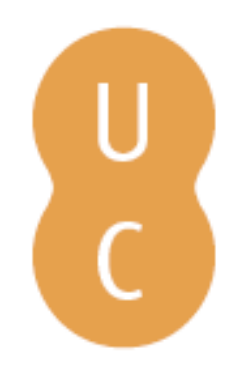

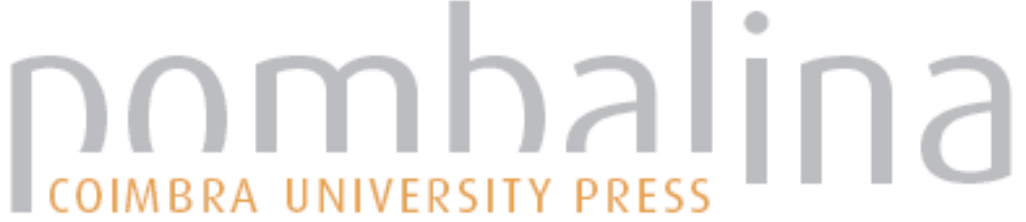

\section{As bases biológicas da Esquizofrenia}

Autor(es): Prata, Diana P.

Publicado por: Imprensa da Universidade de Coimbra

URL

persistente: URI:http://hdl.handle.net/10316.2/35954

DOI: $\quad$ DOI:http://dx.doi.org/10.14195/978-989-26-0852-5_1

Accessed : $\quad$ 26-Apr-2023 14:31:53

A navegação consulta e descarregamento dos títulos inseridos nas Bibliotecas Digitais UC Digitalis, UC Pombalina e UC Impactum, pressupõem a aceitação plena e sem reservas dos Termos e Condições de Uso destas Bibliotecas Digitais, disponíveis em https://digitalis.uc.pt/pt-pt/termos.

Conforme exposto nos referidos Termos e Condições de Uso, o descarregamento de títulos de acesso restrito requer uma licença válida de autorização devendo o utilizador aceder ao(s) documento(s) a partir de um endereço de IP da instituição detentora da supramencionada licença.

Ao utilizador é apenas permitido o descarregamento para uso pessoal, pelo que o emprego do(s) título(s) descarregado(s) para outro fim, designadamente comercial, carece de autorização do respetivo autor ou editor da obra.

Na medida em que todas as obras da UC Digitalis se encontram protegidas pelo Código do Direito de Autor e Direitos Conexos e demais legislação aplicável, toda a cópia, parcial ou total, deste documento, nos casos em que é legalmente admitida, deverá conter ou fazer-se acompanhar por este aviso.

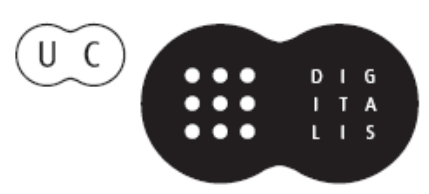





\section{AS BASES BIOLÓGICAS DA ESQUIZOFRENIA*}

\section{Esquizofrenia}

A esquizofrenia é uma doença mental grave que afecta perto de $1 \%$ da população mundial (Capuano, Crosby, \& Lloyd, 2002) em todas as culturas (Schultz, North, \& Shields, 2007), acarretando enormes custos económicos por perda de produtividade e gastos em cuidados de saúde, para além dos efeitos nefastos na qualidade de vida dos doentes e suas famílias (Knapp, Mangalore, \& Simon, 2004).

A doença surge geralmente em adultos jovens, com maior prevalência (Saha, Welham, Chant, \& McGrath, 2006) e início mais precoce (Moriarty et al., 2001), no sexo masculino. Os doentes apresentam uma baixa taxa de matrimónio e altas taxas de divórcio e desemprego de longa duração, o que frequentemente leva à pobreza e à situação de sem-abrigo (Thornicroft et al., 2004); os que têm perturbações psicóticas graves apresentam, mais frequentemente, comportamento agressivo (Hodgins \& Muller-Isberner, 2004). A esperança média de vida mostra uma perda de 12 a 15 anos (Saha, Chant, Welham, \& McGrath, 2005) e o suicídio e a doença cardíaca de progressão rápida são causas frequentes de morte,

* A presente comunicação constitui uma revisão de conhecimentos sobre a etiologia, a fisiopatologia neuro-química e as componentes genéticas do quadro sintomático da esquizofrenia. Na comunicação complementar, "Investigação das Bases Biológicas da Cognição na Esquizofrenia com Imagiologia Genética”, apresentada mais adiante no Workshop 1, encontram-se expostos e discutidos resultados de diversos estudos experimentais e clínicos.

1 (PhD), Bióloga investigadora no Departamento de Estudos sobre Psicoses do Instituto de Psiquiatria de Londres, parte do King's College of London da Universidade de Londres, Reino Unido. E-mail: diana.prata@kcl.ac.uk 
estando a última fortemente associada a depressão, toxicodependência, agitação ou inquietude motora, medo de desintegração mental e fraca aderência ao tratamento (Hawton, Sutton, Haw, Sinclair, \& Deeks, 2005).

O diagnóstico baseia-se no relato das experiências dos doentes e na observação do seu comportamento e caracteriza-se pela existência de sintomas ditos (1) positivos, (2) negativos e (3) cognitivos: 1) os sintomas positivos incluem aspectos psicóticos tais como alterações do pensamento, alucinações (as auditivas e as visuais são as mais comuns) e delírios que são frequentemente paranóides; 2) os sintomas negativos incluem isolamento social, perda de motivação ou de prazer e embotamento afectivo; 3) os sintomas cognitivos incluem alterações em muitos domínios da função cognitiva: função executiva, atenção, processamento da percepção/motricidade, vigilância, aprendizagem e memória verbais, memória de trabalho verbal e espacial e fluência verbal (i.e. memória semântica) (Freedman, 2003). Como consequência, a resolução de problemas, o planeamento e concretização de objectivos futuros e a tomada de decisões no comportamento e no discurso estão alterados em geral.

As atuais classificações diagnósticas não são ainda completamente satisfatórias existindo elevada heterogeneidade entre os doentes. A esquizofrenia partilha com outras perturbações psiquiátricas várias características epidemiológicas tais como a idade de início, o risco ao longo da vida, a distribuição mundial, o risco de suicídio e o grau de susceptibilidade genética, bem como alguma sintomatologia. A doença tem co-morbilidade, em particular, com a depressão unipolar com características psicóticas, a doença bipolar (maníaco-depressiva), e as alterações de personalidade esquizoafectivas, delirantes, esquizofreniformes, esquizóides e esquizotípicas ou o transtorno psicótico 'sem outra especificação' (Craddock \& Owen, 2005). De facto, a ideia de um continuum psiquiátrico alargado desde a depressão unipolar, passando pela doença bipolar e a perturbação esquizoafectiva até à esquizofrenia está a ser cada vez mais apoiada por achados genéticos, bioquímicos e farmacológicos (Cardno et al., 1999; Berrettini, 2003; Prata et al., 2007; Breen et al., 2006) embora nem sempre (Prata et al., 2006). Pensa-se que certos factores de risco genéticos e ambientais são comuns aos vários estados psiquiátricos. 
Desde os anos 50 que existe tratamento farmacológico para a esquizofrenia e para as alterações do foro psicótico, ainda que com eficácia variável. Os primeiros antipsicóticos a surgir foram os antagonistas dos receptores da dopamina tipo D2 (i.e. de primeira geração ou 'típicos', ex., clorpromazina e haloperidol). No entanto, ao mesmo tempo que melhoram os sintomas positivos (psicóticos), estes fármacos aumentam geralmente o risco de efeitos secundários ditos extrapiramidais (relacionados com a coordenação motora), tais como reações distónicas (ex., espasmos musculares), sintomas de parkinsonismo (ex., tremores), acinésia (incapacidade de iniciar movimento) e acatísia (incapacidade de permanecer imóvel) e discinésiatardia (movimentos involuntários repetitivos). Posteriormente emergiram os antipsicóticos de segunda geração ('atípicos', ex., clozapina, risperidona, sertindole, olanzapine e quetiapina) que combinam o antagonismo dos receptores da dopamina D2 com o antagonismo dos receptores da serotonina. Estes parecem apresentar maior eficácia (50-80\% dos doentes mostram alguma melhoria (Robinson, Woerner, Delman, \& Kane, 2005) e menor risco de efeitos secundários extrapiramidais do que os típicos mas um risco superior de efeitos secundários metabólicos tais como a diabetes, a hipercolesterolémia e o aumento de peso (Lean \& Pajonk, 2003). Apesar dos tratamentos farmacológicos serem eficazes para os delírios e as alucinações, são-no em menor grau para os incapacitantes sintomas cognitivos e negativos (i.e. motivacionais). Intervenções vocacionais e psicoterapêuticas, em comunidades de apoio locais ('comunity-based support'), em conjunção com a medicação antipsicótica, podem melhorar o resultado funcional, mas muitas vezes não estão disponíveis.

\subsection{Etiologia}

No que diz respeito à etiologia da esquizofrenia, foram propostas causas ambientais e genéticas tanto no foro do neurodesenvolvimento ou neuroplasticidade estrutural (ex., a hipótese do neurodesenvolvimento) como no da neurotransmissão ou neuroplasticidade sináptica (ex., hipótese 
do glutamato e da dopamina). Focar-nos-emos mais adiante nas hipóteses do foro da neurotransmissão e nas causas genéticas.

A hipótese do neurodesenvolvimento na esquizofrenia datada dos anos 20 postula que factores genéticos ou agressões pré ou perinatais podem ter efeito no desenvolvimento cerebral e conduzir, no cérebro maduro, a anomalias que predispõem à doença (Weinberger, 1987; Murray, O'Callaghan, Castle, \& Lewis, 1992). Corroborando esta hipótese, uma meta-análise recente mostrou que doentes com esquizofrenia têm maior probabilidade de ter sofrido complicações obstétricas, em particular nascimento prematuro, baixo peso à nascença, e hipóxia-isquémia perinatal, do que a população em geral (Clarke, Harley, \& Cannon, 2006). Postula-se que a causa da lesão que impede o desenvolvimento neurológico normal seja a herança de genes anómalos ou uma eventual adversidade fetal ou neonatal (ex., no momento do parto ou consumo de substâncias tóxicas ou diabetes durante a gravidez) ou a interação entre ambas. A análise post-mortem de cérebros de doentes esquizofrénicos revela alterações que podem estar relacionadas com perturbações do desenvolvimento neurológico nomeadamente no hipocampo e nos lobos pré-frontal e temporal superior (Weinberger, 1999). O alargamento ventricular, a diminuição do volume cerebral e as alterações na espessura do córtex, na girificação, na estrutura do hipocampo e na assimetria cerebral observados nalguns doentes esquizofrénicos antes de qualquer medicação antipsicótica, podem ser o resultado de uma cascata iniciada precocemente durante o desenvolvimento neurológico (Steen, Mull, McClure, Hamer, \& Lieberman, 2006). É de notar que mais de $50 \%$ dos genes implicados na esquizofrenia estão também sujeitos a regulação pela hipóxia (e.g. $A K T 1, B D N F$, COMT, DNTBP1, GRM3, NRG1, PRODH, RELN e RGS4) (Schmidt-Kastner, van, Steinbusch, \& Schmitz, 2006; Lang, Puls, Muller, Strutz-Seebohm, \& Gallinat, 2007) o que suporta a ideia de uma influência da interação gene $\mathrm{x}$ ambiente.

Factores ambientais externos tais como acontecimentos marcantes ou stressantes ao longo da vida também foram propostos como causas da esquizofrenia. Esta sugestão é baseada no achado de que os doentes esquizofrénicos experienciam significativamente mais acontecimentos 
marcantes ou stressantes antes do início da doença ou das recaídas (Brown \& Birley, 1968; Bebbington et al., 1993). Na idade adulta, nomeadamente o isolamento social, a situação de migrante e a vida urbana são factores ambientais de stress que parecem contribuir para o despoletar da esquizofrenia (Boydell, van, McKenzie, \& Murray, 2004). Outro factor ambiental importante é o uso de drogas psicotrópicas. O contacto com o dronabinol, o principal componente psicotrópico do cannabis, provoca estados psicóticos ligeiros e transitórios (Morrison et al., 2009), para os quais os indivíduos com vulnerabilidade pré-existente para a psicose estão mais susceptíveis (Henquet et al., 2006). O uso de cannabis, especialmente no início da adolescência, mostrou aumentar até quatro vezes o risco do aparecimento de esquizofrenia no futuro (Arseneault et al., 2002; Henquet et al., 2005; Moore et al., 2007). A vulnerabilidade a este factor de stress ambiental pode por sua vez aumentar consoante a constituição genética do indivíduo (i.e. depender de uma interação gene $\mathrm{x}$ ambiente) tal como foi proposto depois da observação de que uma variação na enzima que metaboliza a dopamina, a catecol-O-metiltransferase (COMT), afecta a propensão para o desenvolvimento de psicose em indivíduos que usaram cannabis na adolescência (Caspi et al., 2005). Mesmo assim, apenas uma pequena percentagem das pessoas que usam cannabis desenvolvem psicose (abaixo dos 10\%). Outros hipotéticos factores ambientais de risco incluem a estação do ano e o local de nascimento, o estatuto socioeconómico e as infecções maternas, mas os dados que apoiam estas sugestões são ainda inconclusivos (Bromet \& Fennig, 1999). Resumindo, a susceptibilidade para a esquizofrenia parece advir de uma interação entre factores genéticos e ambientais que podem causar anomalias no neurodesenvolvimento (fetal e peri-natal) e/ou na neurotransmissão em idade adulta (Lewis \& Lieberman, 2000).

\subsection{Fisiopatologia neuroquímica}

Vários sistemas de neurotransmissão cerebral parecem estar afectados nos doentes com esquizofrenia, embora não seja ainda absolutamente 
claro se estas alterações provocam o desenvolvimento de esquizofrenia ou se representam uma consequência da progressão da doença ou do tratamento. Existem duas hipóteses principais para a fisiopatologia da esquizofrenia, as quais foram construídas à volta de anomalias relacionadas com a neurotransmissão: a hipótese da dopamina e a do glutamato. Estas não são de modo nenhum mutuamente exclusivas e existe evidência que apoia um cenário no qual ambas coexistem, num grau variável, na esquizofrenia.

\subsubsection{Hipótese da dopamina}

A hipótese neuroquímica da esquizofrenia mais amplamente considerada é a hipótese da dopamina que postula que os sintomas positivos na esquizofrenia provêm da hiperestimulação dos receptores D2 da dopamina causada por um excesso de dopamina subcortical. A hipótese surgiu de duas observações iniciais: (1) que uma exposição continuada aos receptores agonistas D2 induz os sintomas positivos (Laruelle et al., 1996) característicos da esquizofrenia e (2) que todos os medicamentos com efeitos antipsicóticos comprovados bloqueiam em certo grau os receptores D2 (Carlsson, 1978; Seeman, Chau-Wong, Tedesco, \& Wong, 1975; Creese, Burt, \& Snyder, 1976). De facto, apesar do interesse recente noutros sistemas de neurotransmissores, os receptores tipo D2 da dopamina ainda são o alvo principal dos medicamentos antipsicóticos (Kapur \& Mamo, 2003).

O aparecimento da hipótese da dopamina impulsionou vários laboratórios a procurar evidência direta de anomalias no sistema dopaminérgico no cérebro de indivíduos com esquizofrenia (Angrist, Rotrosen, \& Gershon, 2001). A hipótese foi, de facto, apoiada por estudos em doentes que mostraram uma sensibilidade aumentada aos efeitos psicogénicos de agentes que aumentam a libertação sináptica de dopamina, como, por exemplo, as anfetaminas (Davidson et al., 1987; Angrist, Rotrosen, \& Gershon, 1980; Laruelle et al., 1996) e uma maior transmissão de dopamina do estriado in vivo. Esta última observação, conseguida com tomografia 
de emissão de positrões (PET) (Breier et al., 1997; Abi-Dargham et al., 1998; Laruelle \& Abi-Dargham, 1999; Laruelle, Abi-Dargham, Gil, Kegeles, \& Innis, 1999), mostrou uma maior densidade de receptores dopamina D2 cerebrais em doentes (Seeman \& Kapur, 2000). Em acréscimo, a anfetamina (agonista da dopamina) parece mimetizar sintomas de tipo-psicótico mesmo em indivíduos saudáveis (Angrist, Shopsin, \& Gershon, 1971). Contudo, a hipótese da dopamina não tem sido consistentemente apoiada pelas medições da densidade de receptores de dopamina ou dos níveis de metabolitos, tanto post-mortem como in vivo (Talkowski, Bamne, Mansour, \& Nimgaonkar, 2007), mas as discrepâncias podem ser devidas a efeitos de medicação ou plasticidade neuronal. Também têm surgido discrepâncias em estudos de associação de genes reguladores de dopamina, as quais podem ser devidas a um tamanho variável ou uma elevada heterogeneidade das amostras (étnica e fenotípica). Em suma, apesar destas últimas medições estáticas dos mecanismos dopaminérgicos terem falhado em revelar anomalias significativas na esquizofrenia, os estudos dinâmicos, mencionados acima, têm sido mais positivos. Pelo menos os sintomas positivos da esquizofrenia parecem estar associados a um aumento na libertação sináptica de dopamina juntamente com uma possível hiper-sensibilização às ações da dopamina (Seeman et al., 2005; Iversen \& Iversen, 2007).

Assim, foi desenvolvido um modelo explicativo para o mecanismo desencadeador dos sintomas positivos da esquizofrenia, o qual integra a hipótese da dopamina (Kapur, 2003). De acordo com esta teoria, a libertação de dopamina no estriado ventral dá um sinal de que um dado estímulo ou acontecimento é importante (i.e. saliente ou relevante). Na esquizofrenia, a subjacente libertação elevada de dopamina nestes neurónios poderá ser responsável pelas alucinações e delírios através da atribuição de uma importância e significado pessoal exagerados a acontecimentos internos e externos normais. Assim, para uma pessoa com esquizofrenia, vários estímulos se tornam carregados de importância e significado.

A hipótese clássica da dopamina na esquizofrenia foi depois revisitada para incluir os sintomas negativos e cognitivos (Davis, Kahn, Ko, \& Davidson, 1991). Postulou-se que estes sintomas derivam de um défice de 
dopamina no córtex, o qual resulta na hipo-estimulação dos receptores de dopamina D1 (o subtipo predominante nesta área do cérebro). A hipótese revisitada da dopamina propõe a coexistência, na esquizofrenia, de um défice de dopamina no córtex (nomeadamente o pré-frontal, resultando principalmente numa hipo-estimulação dos receptores D1) e um excesso de dopamina subcortical (conduzindo principalmente à hiperestimulação dos receptores D2), estando os dois fenómenos aparentemente correlacionados (Abi-Dargham, 2004; Grace, 2000; Weinberger et al., 2001; Howes et al., 2007). Assim, em vez de uma hiperatividade dopaminérgica geral, uma desregulação dopaminérgica parece ser mais apropriada para caracterizar a esquizofrenia (Figura 1).

Várias observações apoiam esta revisão da hipótese da dopamina. Em 1979, Brozoski et al., (Brozoski, Brown, Rosvold, \& Goldman, 1979; Brozoski et al., 1979) reportaram que uma diminuição seletiva de dopamina no córtex pré-frontal dorso-lateral em macacos perturbava a performance da memória de trabalho espacial a qual era posteriormente restabelecida por um tratamento com agonistas da dopamina. De facto, desde então, tem-se acumulado um vasto conjunto de estudos mostrando que a transmissão dopaminérgica no córtex pré-frontal é essencial para uma função cognitiva normal (Sawaguchi \& Goldman-Rakic, 1994; Williams \& Goldman-Rakic, 1995). A sua alteração, nomeadamente a bipo-função, tem sido amplamente associada a perturbações cognitivas na esquizofrenia (Weinberger, Berman, \& Chase, 1988; Akil et al., 1999; Weinberger et al., 2001; Abi-Dargham et al., 2002; Akil et al., 2003). Estudos recentes das consequências funcionais do polimorfismo Val158Met da enzima COMT (metabolizadora da dopamina) também apoiam fortemente o envolvimento da dopamina cortical na função cognitiva. Verificou-se que tanto o "knock-out" genético da COMT em ratos (Huotari et al., 2002; Gogos et al., 1998; Yavich, Forsberg, Karayiorgou, Gogos, \& Mannisto, 2007) como os inibidores de COMT (Khromova, Rauhala, Zolotov, \& Mannisto, 1995; Liljequist, Haapalinna, Ahlander, Li, \& Mannisto, 1997; Tunbridge, Bannerman, Sharp, \& Harrison, 2004) ao evitarem a degradação da dopamina cortical aumentavam os níveis de dopamina pré-frontal (mas não a do estriado) e favoreciam a memória e a aprendizagem. Relativamente 
à estrutura cerebral, Akil et al. (1999) registaram uma reduzida enervação dopaminérgica no córtex pré-frontal na esquizofrenia. Tal não foi detectado em macacos tratados com o antipsicótico haloperidol quando comparados com macacos-controlo e, portanto, não parece ser farmacologicamente induzido. Também Abi-Dargham et al. (2002) encontraram maior disponibilidade de receptores D1 no córtex pré-frontal de indivíduos esquizofrénicos (nunca medicados ou temporariamente sem medicação), a qual foi fortemente associada à fraca memória de trabalho. Tal pode representar uma sobre-regulação compensatória (mas ineficaz) secundária a uma deficiência sustentada de dopamina pré-frontal. Contudo, também tem havido resultados contraditórios que revelam uma diminuição significativa na disponibilidade pré-frontal de receptores D1 em esquizofrénicos nunca medicados ou nenhuma diferença (Okubo et al., 1997).

$\mathrm{Na}$ questão da resposta dos sintomas negativos e cognitivos à medicação antipsicótica, existe alguma controvérsia. Estudos que indicam melhoria referem-se normalmente a sintomas negativos 'secundários' (i.e. menor interação social devido a uma crescente preocupação com experiências internas) e vários não reportaram qualquer efeito (Javitt, 2001). Os sintomas cognitivos também são por vezes vistos como um aspecto relativamente independente na esquizofrenia (Tamminga, Buchanan, \& Gold, 1998). Contudo, alguns estudos mostram que os sintomas cognitivos melhoram com antipsicóticos atípicos embora não significativamente com os típicos (Bilder et al., 2002). Tal é consistente com o facto dos medicamentos atípicos serem antagonistas D2 relativamente menos eficazes da projeção dopaminérgica mesocortical da área tegumental ventral (ATV) para o córtex pré-frontal do que os típicos, apesar de eles também bloquearem efetivamente efeitos pós-sinápticos da projeção dopaminérgica mesolímbica da ATV para o córtex límbico. Por outras palavras, os antipsicóticos atípicos têm uma menor afinidade para os receptores D2 corticais do que para os estriatais e, possivelmente também devido à sua capacidade para também bloquearem os receptores 5HT2A da serotonina (Honey et al., 1999), estão associados a um aumento na atividade dopaminérgica cortical (em ratos) (Moghaddam \& Bunney, 1990; Westerink, de Boer, de Vries, Kruse, \& Long, 1998; Kuroki, Kawahara, Yonezawa, \& Tashiro, 
1999). Apesar dos estudos de memória de trabalho e atenção terem sido inconclusivos (Meltzer \& McGurk, 1999), a fluência verbal (Hagger et al., 1993), em particular, tem mostrado melhorar marcadamente com a administração do antipsicótico atípico clozapina. É de notar que os sintomas cognitivos estão associados à desregulação da dopamina não apenas na esquizofrenia mas também noutras doenças ou condições: nas doenças de Huntington (Cha et al., 1998) e de Parkinson (Gotham, Brown, \& Marsden, 1988), na depressão (Jimerson et al., 1984), na toxicodependência (Wise, 1998) e no envelhecimento normal (Volkow et al., 1998).

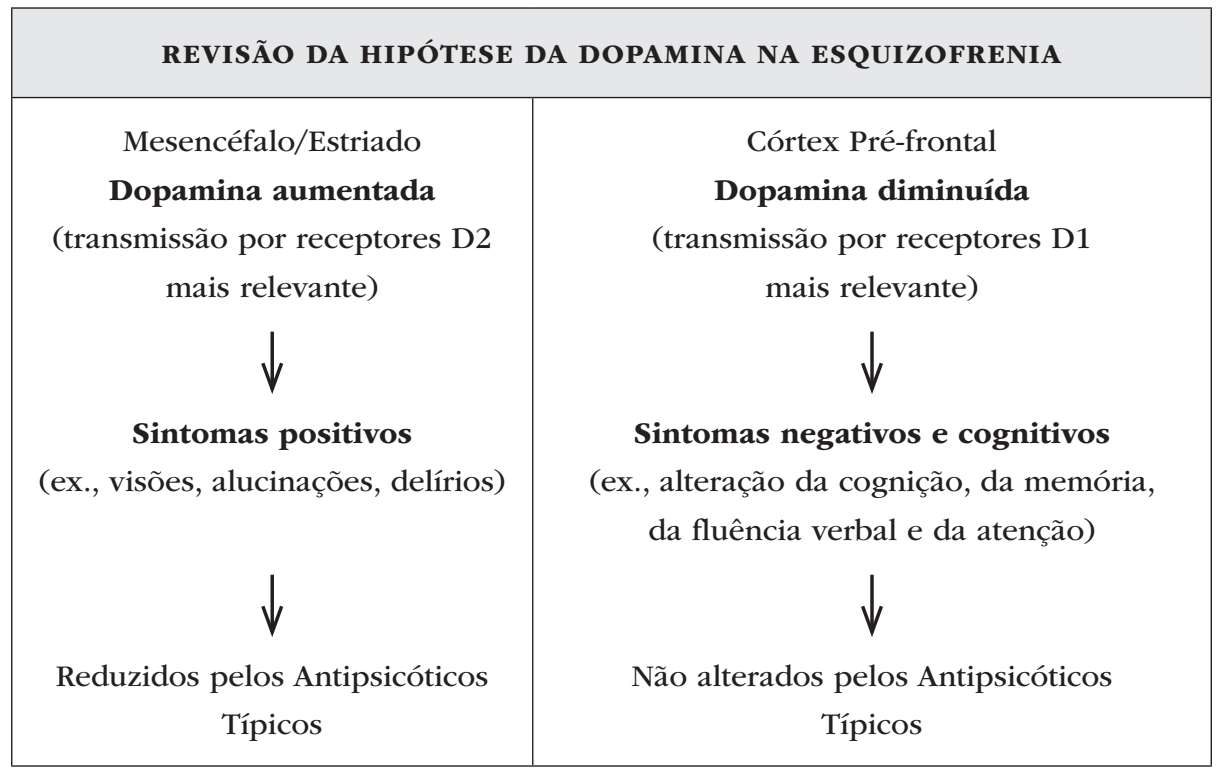

Figura 1. As relações entre os sintomas da esquizofrenia e a transmissão da dopamina.

Em termos de causalidade, tem sido proposto que, na esquizofrenia, são primários os défices negativos e cognitivos resultantes de insuficiência de dopamina pré-frontal cortical e secundários (consequentes) os sintomas positivos provenientes da hiperfunção dopaminérgica no estriado. Neste modelo, a hipo-função nos circuitos neuronais pré-frontais, característica da esquizofrenia, leva à desinibição da atividade no mesencéfalo e 
no estriado com um resultante estado híper-dopaminérgico no estriado. Tal é consistente com a observada relação recíproca entre a atividade dopaminérgica cortical e a subcortical (Sesack \& Carr, 2002; Meyer-Lindenberg et al., 2002; Abi-Dargham \& Moore, 2003). De facto, a atividade dos terminais de dopamina no estriado está sob o controlo do córtex pré-frontal. A estimulação do córtex pré-frontal, a frequências relevantes para as funções cognitivas, inibe a libertação de dopamina no núcleo acumbente (um componente do estriado) (Jackson, Frost, \& Moghaddam, 2001). O mecanismo de regulação envolve projeções diretas e indiretas a partir do córtex para o mesencéfalo e estriado, através de eferentes glutamatérgicos que partem do córtex pré-frontal (Christie, Bridge, James, \& Beart, 1985). Em concordância, a ruptura da neurotransmissão glutamatérgica com cetamina em seres humanos leva ao aumento da libertação de dopamina no estriado (Kegeles et al., 2000). Adicionalmente, a COMT, que tem um papel importante na regulação dos níveis de dopamina no córtex pré-frontal mas não do estriado, mostrou modular a expressão da tirosina hidroxilase (a enzima limitante na síntese de dopamina) no mesencéfalo, especificamente em neurónios que projetam para o estriado e para a amígdala (Akil et al., 2003). Também se observou que a COMT modula a captação ('uptake') de levodopa (um precursor de dopamina) no mesencéfalo durante uma tarefa cognitiva, o que é indicativo de um aumento da síntese de dopamina nesta região (Meyer-Lindenberg et al., 2005). Dado que as projeções do córtex pré-frontal que fazem sinapse na ATV (mesencéfalo) o fazem nos neurónios que projetam para o núcleo acumbente os quais são GABAérgicos (inibidores) (Carr \& Sesack, 2000), isto sugere um mecanismo anatómico direto pelo qual um decréscimo patológico no resultado ('output') excitatório do córtex pré-frontal (putativamente presente na esquizofrenia) conduz a uma desinibição da função dopaminérgica do estriado. De acordo com isto, o estudo de Bertolino et al. (Bertolino et al., 2000) demonstrou uma correlação, apenas em doentes esquizofrénicos, entre a redução de N-acetil-aspartato, um marcador de integridade neuronal, no córtex pré-frontal e a libertação exagerada de dopamina induzida por administração de anfetamina no estriado. Posteriormente, Meyer-Lindenberg et al. (2002) mostraram num 
estudo de PET que a baixa atividade do córtex pré-frontal estava associada a um aumento da atividade dopaminérgica no estriado de doentes esquizofrénicos mas, mais uma vez, não significativamente em indivíduos saudáveis. Estes resultados apoiam a hipótese que na esquizofrenia uma patologia neuronal no córtex pré-frontal está diretamente relacionada com (e é pelo menos parcialmente responsável pela) síntese e secreção anormalmente altas de dopamina no estriado. Estas podem, por sua vez, exacerbar os défices cognitivos sediados no córtex.

O modo como a doença é desencadeada e a razão pela qual os doentes com esquizofrenia não têm geralmente sintomas psicóticos positivos até ao início da idade adulta permanece no domínio da especulação. Estas mudanças subtis refletem provavelmente a existência de uma sucessão de eventos em cadeia e portanto vários factores de risco devem estar presentes, o que é consistente com um modelo multifactorial da esquizofrenia.

\subsubsection{Hipótese do glutamato}

Várias linhas de evidência apontam para a hipótese de que a disfunção dopaminérgica na esquizofrenia é causada, pelo menos parcialmente ou nalguns casos, por uma disfunção glutamatérgica subjacente, como previamente mencionado. Neste modelo, a hipo-função glutamatérgica nas projeções córtico-estriatais conduz a um efeito de 'abertura' no ciclo ('loop') tálamo-cortical que resulta numa 'inundação' sensorial exagerada e consequentemente nos sintomas psicóticos e nas já conhecidas alterações das concentrações de dopamina.

Corroborando a hipótese do glutamato, antagonistas dos receptores de NMDA tal como a fenciclidina, a cetamina e o MK-801 são potentes ativadores da libertação de dopamina e, portanto, podem causar fortes sintomas psicóticos em indivíduos saudáveis e no exacerbar dos sintomas em doentes esquizofrénicos (Krystal et al., 1994). A perda da função glutamatérgica na esquizofrenia é também apoiada pela observação de uma diminuída densidade do transportador de glutamato nas estruturas estriatais que recebem as projeções glutamatérgicas corticais. Défices 
no transportador-1 vesicular do glutamato tanto no estriado como no hipocampo apoiam esta observação, e a densidade de transportadores está associada ao risco de desenvolvimento de esquizofrenia (Reynolds \& Harte, 2007).

Mais recentemente foi desenvolvido o primeiro agonista seletivo para os receptores metabotrópicos do glutamato, sendo o primeiro antipsicótico que não atua como antagonista da dopamina (Patil et al., 2007). O medicamento que parece apresentar uma melhoria dos sintomas positivos e negativos é comparável à olanzapina sem provocar os efeitos secundários de elevação da prolactina, sintomas extrapiramidais ou aumento de peso.

\subsection{Etiologia Genética}

A esquizofrenia é uma doença psiquiátrica com uma forte componente genética (Rutter, 2006) mas a identificação de genes de risco específicos tem sido problemática devido à complexidade e heterogeneidade do fenótipo e a uma muito provável contribuição poligénica mais ou menos dependente de factores ambientais. A doença não parece estar relacionada com variações (i.e. polimorfismos) de largo efeito num único gene mas sim com variações de efeito modesto em vários genes (Owen, Craddock, \& Jablensky, 2007). Estes genes estão em geral envolvidos em aspectos estruturais do cérebro (tais como o neurodesenvolvimento, neuroplasticidade estrutural, mielinização e sinaptogénese) e/ou funcionais (neuroplasticidade sináptica e neurotransmissão, nomeadamente a dopaminérgica, glutamatérgica e serotonérgica). A aplicação da genética ao estudo das perturbações psiquiátricas visa contribuir para a compreensão dos mecanismos fisiológicos subjacentes, identificar potenciais défices específicos (ex., cognitivos) para uma intervenção específica, conduzir ao desenvolvimento de novos fármacos e tratamentos personalizados (farmacogenética), identificar indivíduos de alto risco para uma intervenção precoce (através da criação de biomarcadores) e, eventualmente, melhorar a classificação diagnóstica, o que seria útil para a investigação em geral ao reduzir a heterogeneidade nos diagnósticos. 


\subsubsection{Hereditariedade}

Na primeira década do séc. XX, Kraepelin descreveu pela primeira vez a 'dementiapraecox' (i.e. esquizofrenia) como uma doença hereditária (1896), e, subsequentemente foram realizados grandes estudos coorte ('cohort') que mostraram claramente que esta doença se agrega em famílias. Tal foi confirmado posteriormente em estudos de genética quantitativa (ex., estudos em gémeos, em famílias e de adopção), um campo dedicado à medição do impacto relativo das influências genéticas versus as não-genéticas na variância de uma determinada condição na população (i.e. questiona em que grau uma determinada condição é hereditária) (Rutter, 2006). Existe agora, a partir desses estudos, evidência considerável de que a contribuição genética para a etiologia da esquizofrenia é cerca de $80 \%$, o que indica tratar-se de uma doença fortemente hereditária. Cinco estudos em gémeos, sistematicamente revistos em Cardno e Gottesman (2000), reportaram que a taxa de concordância para a esquizofrenia em gémeos monozigóticos é de 41-65\% comparada com 0-28\% para pares dizigóticos, dando origem a estimativas de hereditariedade da ordem dos $80 \%$. A mesma estimativa foi obtida em dois estudos de populações europeias (Cannon, Kaprio, Lonnqvist, Huttunen, \& Koskenvuo, 1998; Cardno et al., 1999). Um estudo de adopção dinamarquês concluiu que cerca de $8 \%$ dos familiares biológicos em $1 .^{\circ}$ grau dos adoptados com esquizofrenia tinham eles próprios esquizofrenia, comparados com apenas menos de $1 \%$ dos familiares em $1 .^{\circ}$ grau de indivíduos saudáveis (Kendler, Gruenberg, \& Kinney, 1994). Esta taxa foi confirmada em várias investigações numa amostra finlandesa (Tienari et al., 2004). Por último, os estudos em famílias também mostraram consistentemente que o risco de esquizofrenia de um familiar de um indivíduo esquizofrénico é função da extensão na qual eles partilham os seus genes: familiares em $3 .^{\circ}$ grau têm prevalência de $2 \%$; familiares em $2 .^{\circ}$ grau têm $2-6 \%$ enquanto familiares em $1 .^{\circ}$ grau têm 6-17\% (Gottesman, 1991). No entanto, a falta de $100 \%$ de concordância entre gémeos monozigóticos, a diferença entre o risco de gémeos dizigóticos e o de irmãos não-gêmeos e os efeitos de imprinting que por vezes são observados (Francks et al., 2003) são 
provavelmente explicados por factores epigenéticos (responsáveis por diferenças herdáveis no grau de expressão dos genes) que até agora são largamente não mensuráveis, e por factores ambientais (DeLisi \& Fleischhaker, 2007).

Com efeito, os resultados provenientes de estudos em gémeos e famílias não são consistentes com um modelo de transmissão de um único locus génico, mas antes com um que tome em consideração efeitos poligénicos e ambientais. Este é o modelo do limiar multifactorial da esquizofrenia (Picchioni \& Murray, 2007). Este modelo assume que a esquizofrenia tem um carácter limiar, i.e. que existe uma propensão gradual para a esquizofrenia como uma soma de factores (factores genéticos, epigenéticos e ambientais) que apresenta uma distribuição normal (gaussiana) na população geral (McGue, Gottesman, \& Rao, 1983). O modelo considera que qualquer indivíduo tem alguma (maior ou menor) propensão para desenvolver a doença - dada uma combinação individual dos factores acima mencionados - mas a sua expressão ocorre apenas quando esta excede um certo limiar conceptual ao longo do continuum. Deste modo, uma causalidade multifactorial pode traduzir-se num fenótipo dicotomizado (indivíduos afectados versus não-afectados) (Figura 2).

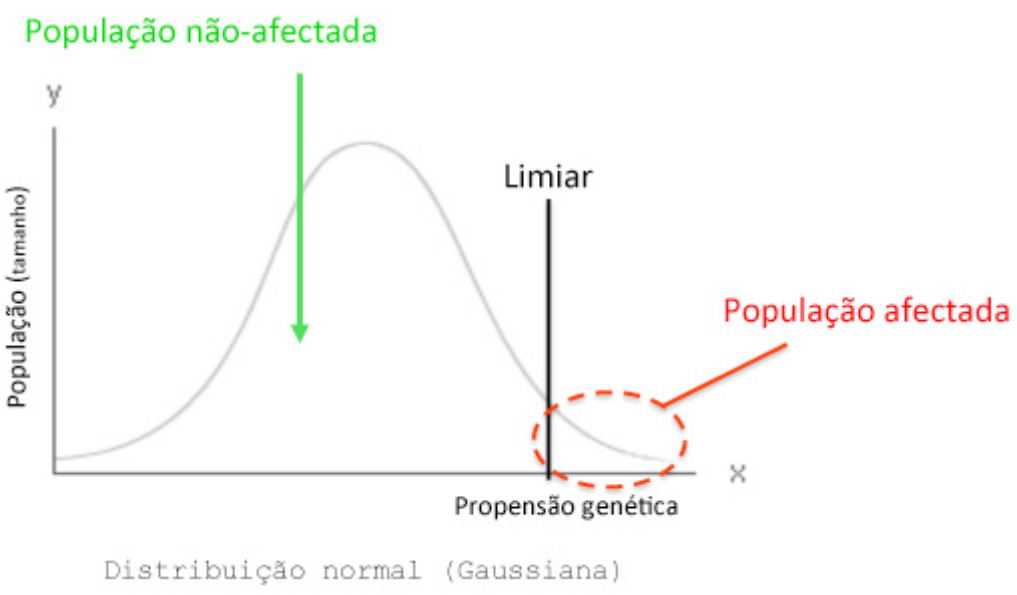

Figura 2. O modelo do limiar multifactorial da susceptibilidade para a esquizofrenia. 


\subsubsection{Linkage e Associação}

A genética molecular tenta identificar os genes (e respectivos polimorfismos e seus alelos) responsáveis pelos efeitos genéticos que oferecem propensão para um dado fenótipo como a esquizofrenia. Este campo de investigação engloba os estudos de linkage e de associação.

Os estudos de linkage averiguam se existe uma co-herança sistemática entre uma dada região cromossómica e um fenótipo. Identificam vastas regiões cromossómicas no genoma que são transmitidas com a doença em famílias e que portanto deverão conter um gene de risco. Cada uma destas regiões é identificada usando um marcador polimórfico (chamado, neste caso, 'posicional'). Duas meta-análises em esquizofrenia, usando diferentes métodos, reportaram resultados simultaneamente sobrepostos e distintos. Usando diferentes métodos, uma destaca as regiões $8 \mathrm{p}, 13 \mathrm{q}$ e 22q (Badner \& Gershon, 2002) e a outra as 2q, 5q, 3p, 11q, 6p, 1q, 22q, 8p, 20q e 14p, e, de modo mais ténue as 16q, 18q, 10p, 15q, 6q e 17q (Lewis et al., 2003).

Os estudos de associação pretendem encontrar uma associação estatística entre alelo(s) de um marcador polimórfico específico e a presença ou ausência de um fenótipo. Os polimorfismos usados pertencem a, ou estão na proximidade de, genes candidatos. Podem ser funcionais (i.e. induzir diretamente alterações ao nível da expressão de mRNA ou do desempenho da proteína) ou estarem co-localizados (i.e. serem frequentemente co-transmitidos) com um polimorfismo (ainda não identificado), esse sim, de real impacto funcional na susceptibilidade para a esquizofrenia. Os marcadores são escolhidos pela sua função (ex., os que codificam intervenientes dos sistemas dopaminérgicos e serotonérgicos sobre os quais as medicações antipsicótica atuam, ou que codificam proteínas com papel relevante no neurodesenvolvimento, ou que simplesmente expressam níveis alterados nos doentes) ou pela sua posição no genoma (ex., os que estão localizados numa região cromossómica associada à esquizofrenia sugerida por um estudo de linkage). Um outro método, mais recente, dispensa hipóteses prévias: a Genome-WideAssociation (GWA) tenta igualmente encontrar uma associação entre um fenótipo e um polimorfismo 
genético mas pesquisando todo o genoma humano, usando um painel de marcadores polimórficos puramente posicionais dispersos ao longo do genoma. Com qualquer destes métodos, são comummente usados dois tipos alternativos de design: utilizando famílias, onde a probabilidade de transmissão do putativo alelo de risco para membros doentes é medida; ou utilizando amostras caso-controle onde é medida a diferença em termos da frequência do putativo alelo de risco entre um grupo de doentes e um grupo de indivíduos saudáveis (controle). Marcadores tais como polimorfismos de um único nucleótido (single nucleotidepolimorphisms, SNPs), inserções-deleções (InDels), loci com variações no número de cópias (copynumbervariations, CNVs), repetições de sequência simples (simplesequencerepeats, SSR), repetições em tandem de número variável (variablenumber tandem repeats, VNTR) (as quais incluem minissatélites e microssatélites ou repetições em tandem curtas, short tandem repeats, STRs) são geralmente usados.

Vários genes têm merecido atenção como genes ditos candidatos para influenciar a susceptibilidade para a esquizofrenia. Genes candidatos inicialmente apenas posicionais, tais como os que codificam a NRG1 (neuregulina-1), o DAOA (G72) (ou DAOA; ativador da D-aminoácido oxidase), a DAO (D-aminoácido oxidase) e a DTNBP1 (disbindina-1) foram primeiramente identificados por estudos de linkage e o DISC1 (disrupted-in-schizophrenia 1) por translocação cromossómica. Os genes para a COMT (catecol-O-Metiltransferase), a PRODH (prolina desidrogenase), o RGS4 (regulador da proteína sinalizadora-4), a MAOA (monoaminaoxidase A), o 5-HTT (transportador de serotonina), o DAT (transportador de dopamina), o DRD2 (receptor D2 de dopamina) e o BDNF (factor neurotrófico derivado do cérebro) são genes candidatos ditos funcionais, sendo o COMT e o PRODH também posicionais pois foram concorrentemente identificados por uma deleção cromossómica. Na tabela 1 estão sumarizados os resultados cumulativos até Janeiro de 2008 das associações positivas e negativas destes genes com a esquizofrenia. 
Tabela 1. Número total de resultados de associação significativa positiva e negativa de vários genes candidatos para a esquizofrenia publicados até Janeiro de 2008. Estão indicados o nome do gene, respectiva localização cromossómica, estudo original (i.e. primeiro) e etnia da amostra ( $c=$ Caucasiana; $a=$ Asiática; $b=$ negra; h=hispânica; o= outra/mistura). (Fonte: http://www.schizophreniaforum.org/res/ sczgene/default.asp) (Allen, Bagade, Tanzi, \& Bertram, 2008).

\begin{tabular}{|c|c|c|c|c|}
\hline \multicolumn{5}{|c|}{ ESTUDOS DE ASSOCIAÇÃO GENÉTICA NA ESQUIZOFRENIA } \\
\hline Gene & Crom. & Original & Positivo & Negativo \\
\hline \multicolumn{5}{|c|}{ Principalmente envolvidos na neurotransmissão cerebral } \\
\hline $\begin{array}{c}\text { COMT } \\
\text { (Catecol-O- } \\
\text { Metiltransferase) }\end{array}$ & 22q11 & $\begin{array}{l}\text { Neg.: (Daniels et al., } \\
\text { 1996) }\end{array}$ & $\begin{array}{c}11(\mathrm{c}) \\
5(\mathrm{a}) \\
5(\mathrm{o} / \mathrm{m})\end{array}$ & $\begin{array}{c}26(\mathrm{c}) \\
17(\mathrm{a}) \\
4(\mathrm{o} / \mathrm{m})\end{array}$ \\
\hline $\begin{array}{c}D A T \\
\text { (Transportador da } \\
\text { Dopamina) }\end{array}$ & $5 \mathrm{p} 15$ & Neg.: (Li et al., 1994) & $\begin{array}{c}1(\mathrm{c}) \\
1(\mathrm{o} / \mathrm{m})\end{array}$ & $\begin{array}{c}8(\mathrm{c}) \\
5(\mathrm{a}) \\
5(\mathrm{o} / \mathrm{m})\end{array}$ \\
\hline $\begin{array}{c}\text { DAO } \\
\text { (D-aminoácido Oxidase) }\end{array}$ & $12 q 23$ & $\begin{array}{c}\text { Pos.: (Chumakov et al., } \\
\text { 2002) }\end{array}$ & $\begin{array}{l}4 \text { (c) } \\
1 \text { (a) }\end{array}$ & $\begin{array}{l}4 \text { (c) } \\
4 \text { (a) }\end{array}$ \\
\hline $\begin{array}{c}\text { RGS4 } \\
\text { (Regulador de proteina G } \\
\text { Sinalizadora-4) }\end{array}$ & $1 \mathrm{q} 23$ & $\begin{array}{l}\text { Pos.: (Chowdari et al., } \\
\text { 2002) }\end{array}$ & $\begin{array}{c}12(\mathrm{c}) \\
1(\mathrm{a}) \\
1(\mathrm{o} / \mathrm{m})\end{array}$ & $\begin{array}{c}5(\mathrm{c}) \\
4(\mathrm{a}) \\
1(\mathrm{~b}) \\
1(\mathrm{o} / \mathrm{m})\end{array}$ \\
\hline $\begin{array}{c}\text { PRODH } \\
\text { (Prolina Desidrogenas) }\end{array}$ & $22 \mathrm{q} 11$ & Pos.: (Liu et al., 2002) & $\begin{array}{c}5(\mathrm{c}) \\
1(\mathrm{a}) \\
2(\mathrm{o} / \mathrm{m})\end{array}$ & $\begin{array}{l}8 \text { (c) } \\
1 \text { (a) }\end{array}$ \\
\hline $\begin{array}{c}\text { DISC1 } \\
\text { (Disrupted-in- } \\
\text { schizophrenia 1) }\end{array}$ & $1 \mathrm{q} 42$ & $\begin{array}{l}\text { Neg.: (Wilson-Annan, } \\
\text { Blackwood, Muir, } \\
\text { Millar, \& Porteous, } \\
\text { 1997) }\end{array}$ & $\begin{array}{l}9 \text { (c) } \\
3(\mathrm{a}) \\
1 \text { (b) }\end{array}$ & $\begin{array}{l}3 \text { (c) } \\
2 \text { (a) }\end{array}$ \\
\hline $\begin{array}{c}5 H T T \\
\text { (Transportador da } \\
\text { Serotonina) }\end{array}$ & $17 q 12$ & $\begin{array}{c}\text { Neg.: (Collier et al., } \\
\text { 1996) }\end{array}$ & $\begin{array}{l}2 \text { (c) } \\
6 \text { (a) }\end{array}$ & $\begin{array}{c}16(\mathrm{c}) \\
2(\mathrm{a}) \\
1(\mathrm{o} / \mathrm{m})\end{array}$ \\
\hline $\begin{array}{c}\text { DAOA (G72) } \\
\text { (Activador da } \\
\text { D-aminoácido Oxidase) }\end{array}$ & $13 q 33$ & $\begin{array}{l}\text { Pos.: (Chumakov et al., } \\
\text { 2002) }\end{array}$ & $\begin{array}{c}12(\mathrm{c}) \\
7(\mathrm{a}) \\
4(\mathrm{o} / \mathrm{m})\end{array}$ & $\begin{array}{c}5(\mathrm{c}) \\
1(\mathrm{a}) \\
1(\mathrm{o} / \mathrm{m})\end{array}$ \\
\hline $\begin{array}{c}\text { MAOA } \\
\text { (Monoamina Oxidase A) }\end{array}$ & Xp11 & $\begin{array}{c}\text { Neg.: (Coron et al., } \\
\text { 1996) }\end{array}$ & $1(\mathrm{c})$ & $\begin{array}{l}11(\mathrm{c}) \\
5(\mathrm{a})\end{array}$ \\
\hline $\begin{array}{c}\text { DRD2 } \\
\text { (Receptor D2 da } \\
\text { dopamina) }\end{array}$ & $11 \mathrm{p} 15$ & $\begin{array}{c}\text { Neg.: (Comings et al., } \\
\text { 1991) }\end{array}$ & $\begin{array}{c}11(\mathrm{c}) \\
4(\mathrm{a}) \\
2(\mathrm{o} / \mathrm{m})\end{array}$ & $\begin{array}{c}26(\mathrm{c}) \\
12(\mathrm{a}) \\
3(\mathrm{o} / \mathrm{m})\end{array}$ \\
\hline
\end{tabular}




\begin{tabular}{|c|c|c|c|c|}
\hline \multicolumn{5}{|c|}{ ESTUDOS DE ASSOCIAÇÃO GENÉTICA NA ESQUIZOFRENIA } \\
\hline Gene & Crom. & Original & Positivo & Negativo \\
\hline \multicolumn{5}{|c|}{ Principalmente envolvidos na estrutura cerebral } \\
\hline $\begin{array}{c}\text { BDNF } \\
\text { (Factor Neurotrófico } \\
\text { Derivado do Cérebro) }\end{array}$ & $11 \mathrm{p} 13$ & $\begin{array}{c}\text { Neg.: (Sasaki et al., } \\
\text { 1997) }\end{array}$ & $\begin{array}{c}5(\mathrm{c}) \\
3(\mathrm{a}) \\
1(\mathrm{o} / \mathrm{m})\end{array}$ & $\begin{array}{c}11(\mathrm{c}) \\
8(\mathrm{a}) \\
2(\mathrm{o} / \mathrm{m})\end{array}$ \\
\hline $\begin{array}{c}D T N B P 1 \\
\text { (Disbindina-1) }\end{array}$ & $6 \mathrm{p} 22$ & $\begin{array}{l}\text { Pos.: (Straub et al., } \\
\text { 2002) }\end{array}$ & $\begin{array}{c}10(\mathrm{c}) \\
3(\mathrm{a}) \\
1(\mathrm{~b}) \\
3(\mathrm{o} / \mathrm{m})\end{array}$ & $\begin{array}{c}12(\mathrm{c}) \\
3(\mathrm{a}) \\
1(\mathrm{~b}) \\
1(\mathrm{~h}) \\
3(\mathrm{o} / \mathrm{m})\end{array}$ \\
\hline $\begin{array}{c}\text { NRG1 } \\
\text { (Neuregulina-1) }\end{array}$ & $8 \mathrm{p} 12$ & $\begin{array}{l}\text { Pos.: (Stefansson et al., } \\
\text { 2002) }\end{array}$ & $\begin{array}{c}12(\mathrm{c}) \\
9(\mathrm{a}) \\
1(\mathrm{~b}) \\
2(\mathrm{o} / \mathrm{m})\end{array}$ & $\begin{array}{c}9(\mathrm{c}) \\
2(\mathrm{a}) \\
2(\mathrm{o} / \mathrm{m}) \\
1(\mathrm{~h})\end{array}$ \\
\hline
\end{tabular}

Na Tabela 1, podemos verificar que, excepto para DISC1 e DAOA, os estudos positivos não ultrapassam, em número, os estudos negativos, apesar de cada estudo dever ser efetivamente considerado em termos de tamanho da amostra e poder estatístico. COMT e DRD2 têm sido os genes mais estudados para associação à esquizofrenia. No caso de COMT, isto é parcialmente devido a ter um SNP bem caracterizado que codifica um polimorfismo comum (Val158Met) e tem um impacto plausível na fisiologia da esquizofrenia. O DRD2 também tem recebido muita atenção dado que codifica para o receptor D2 da dopamina que é o principal alvo dos medicamentos antipsicóticos. No entanto, são os genes NRG1 e $D T N B P$ que têm recolhido mais recentemente o maior número de estudos positivos (e totais) e num menor período de tempo. De facto, para além de estar localizado na região cromossómica (8p) de forte ligação com a esquizofrenia, a associação do $N R G 1$ foi apoiada por uma meta-análise nas populações Asiática e Caucasiana (Li, Collier, \& He, 2006). Contudo, variantes genéticas funcionais ou causativas ainda estão para ser identificadas e é possível que a associação obtida em estudos de linkage possa ser devida, apesar de não exclusivamente, a outros genes candidatos posicionais vizinhos (Tosato, Dazzan, \& Collier, 2005). Um cenário similar aplica-se ao DTNBP1. Haplótipos (i.e. constelação de SNPs) neste gene 
foram positivamente associados à esquizofrenia em vários estudos mas uma confirmação robusta tem sido difícil de obter pois têm sido identificados diferentes alelos de risco (Mutsuddi et al., 2006) mesmo em populações da mesma etnia. De facto, estudos que variam em termos de método, de conjuntos de marcadores usados e na definição de fenótipo não devem ser considerados de modo acrítico como replicações (Munafo, Attwood, \& Flint, 2008; Mutsuddi et al., 2006). É necessária mais investigação para compreender como estes genes de risco atuam no contexto da fisiologia do cérebro durante o desenvolvimento dos sintomas da esquizofrenia. Embora as associações positivas de polimorfismos nos genes NRG1 e DTNBP1 terem crescido rapidamente, muito pouco se sabe sobre o seu impacto ao nível celular na esquizofrenia. No entanto, dado que a genética molecular tem evoluído nos últimos anos desde os estudos de linkage e associação de genes candidatos para os estudos GWA (em que atualmente se podem usar até 900.000 marcadores simultaneamente em milhares de indivíduos afectados e indivíduos saudáveis), abrem-se novos horizontes a explorar.

Com os novos métodos de genotipagem ('genotyping') usados para GWA, altamente produtivos e estatisticamente poderosos era esperada a confirmação dos atuais candidatos e a adição de novos genes de susceptibilidade no panorama existente (DeLisi et al., 2007). Esta, mais do que a primeira situação, foi verificada nos dois primeiros estudos GWA da esquizofrenia (O'Donovan et al., 2008; Stefansson et al., 2008). Um deles (O’Donovan et al., 2008), genotipando aproximadamente 500 SNPs em aproximadamente 500 doentes e 3000 indivíduos saudáveis, identificou ZNF804A como o único gene significativamente associado, o que foi replicado em amostras independentes. Este gene codifica uma proteína sem função conhecida, apesar de conter, previsivelmente, domínios para a ligação ao $\mathrm{ADN}$ e ao ião de zinco, sugerindo um papel como regulador da expressão genética. Mesmo noutros loci com forte replicação nas amostras independentes, nenhum evidencia, intrigantemente, genes candidatos funcionais claros com base na atual compreensão da fisiopatologia da esquizofrenia.

O segundo estudo (Stefansson et al., 2008) identificou 66 CNVsde novo através da análise de aproximadamente 10.000 casos de transmissão de 
pais para filhos, a partir da qual três deleções, nas regiões cromossómicas 1q21.1, 15q11.2 e 15q13.3, estavam significativamente associadas à esquizofrenia em duas amostras independentes. Este achado despoletou o atual interesse em CNVs na procura de factores de susceptibilidade para a esquizofrenia. Ao contrário dos polimorfismos comuns (que até então monopolizavam a atenção), existem variações que, ao apresentarem altas taxas de mutação (>1/10.000 meioses), são raras, e estão provavelmente sob pressão de seleção negativa (i.e. são evolutivamente desvantajosas): os CNVsde novo. No entanto, o facto de surgirem de novo, ou seja espontaneamente nos gametas que darão origem ao indivíduo potencialmente afectado e recorrentemente em determinada região cromossómica, possibilita que apesar da pressão negativa, permaneçam na população. Daí puderem ser contribuidores realmente importantes a nível populacional para o risco de perturbações que reduzem a fecundidade dos afectados, tais como a esquizofrenia, o autismo e o atraso mental. Como os autores referem, isto pode explicar parcialmente a razão pela qual não foram ainda encontradas variações comuns que expliquem satisfatoriamente a ocorrência destas perturbações. De facto, as variações comuns associadas à esquizofrenia até agora (na sua maioria SNPs) mostraram um rácio de probabilidade $<1.5$ bastante menor que os rácios de probabilidade destes CNVs que são de 11.5, 14.8 e 2.7. Tais rácios de probabilidade elevados também tornam os CNVs bons candidatos para biomarcadores clinicamente úteis, por exemplo, no diagnóstico e na avaliação de risco.

Embora estatisticamente poderosos, os estudos GWA também têm limitações (Pearson \& Manolio, 2008). A noção de heterogeneidade na amostra é crucial para a interpretação de resultados de GWA. Seria desejável determinar que combinação de polimorfismos prevê melhor o risco de conversão em cada um dos putativos subgrupos etiológicos/diagnósticos, no entanto cada vez mais doentes de vários locais e culturas médicas são agrupados com o intuito de conseguir amostras suficientemente grandes para estudos de GWA. (A própria natureza de um estudo de GWA o exige, dado que ao se escrutinar todo o genoma, a elevada probabilidade de obter falsos positivos tem que ser contrabalançada com um aumento de poder estatístico que permita correções estatísticas aos testes múltiplos). 
A desvantagem é que amostras de origem heterogénea têm maior probabilidade de conter doentes com diferentes etiologias e classificações diagnósticas inconsistentes. Isto dificulta a detecção da constelação de factores causais específicos para cada potencial subgrupo. No entanto, a descoberta de novos factores de risco genético graças aos estudos GWA abre novas e promissoras linhas de investigação sobre os mecanismos biológicos através dos quais eles conferirão risco.

\subsection{Farmacogenética}

Outro uso importante da genética molecular reside no campo emergente da farmacogenética. A farmacogenética tenta identificar polimorfismos genéticos que influenciem a resposta a antipsicóticos, em termos de sintomas positivos, negativos e cognitivos, bem como de efeitos secundários. Existe agora alguma evidência de que a variação entre indivíduos em termos de resposta aos antipsicóticos está associada a polimorfismos nos genes que codificam enzimas, receptores e transportadores com impacto na neurotransmissão (Arranz \& Kapur, 2008). Usando a informação obtida, o objetivo é conceber testes farmacogenétios de previsão, que possam informar a escolha do tipo e dose de medicação mais apropriada para cada doente, por parte do psiquiatra. Um teste farmacogenético consiste numa bateria de um ou mais polimorfismos genéticos relevantes ('biomarcadores') a genotipar para cada doente antes de este receber a receita farmacológica. Tal promete melhorar a eficiência em termos de custo, resultado, segurança, tolerância e aderência ao tratamento e é particularmente útil dado que as respostas imprevisíveis aos tratamentos e os efeitos secundários problemáticos têm comprometido a terapêutica da esquizofrenia desde o seu surgimento. Mesmo a eficácia da última geração de antipsicóticos é muito variável de indivíduo para indivíduo e, como já foi referido, os seus efeitos secundários metabólicos causam uma morbilidade considerável numa população já em risco acrescido de doença cardiovascular e em fraca condição física, além de uma elevada taxa de descontinuação (Lieberman et al., 2005). A farmacogenética pro- 
mete melhorar radicalmente a terapêutica de modo a que a medicina personalizada que visa 'receitar o medicamento certo à pessoa certa' de modo a maximizar o resultado do tratamento e a minimizar os possíveis efeitos secundários, se torne, cada vez mais, uma realidade.

\subsection{Endofenótipos}

As origens genéticas e moleculares das doenças mentais permanecem difíceis de caracterizar, com poucas e notáveis exceções, como a doença de Alzheimer ou a doença de Huntington. Como já foi discutido, isto deve-se provavelmente a uma etiologia poligénica e multifactorial, a estudos com poder estatístico insuficiente, à co-morbilidade e sobreposição sintomatológica entre diferentes categorias de doenças e à grande heterogeneidade dentro de cada categoria o que dificulta uma classificação diagnóstica precisa. Comparando com outras doenças complexas comuns tais como as doenças cardiovasculares ou a diabetes, este campo teve uma relativa falta de foco em endofenótipos quantitativos que indexem o risco da doença (Gottesman \& Gould, 2003). Contudo, a identificação de endofenótipos, além de poder contribuir para a descoberta de potenciais biomarcadores, pode ajudar a melhorar os atuais modelos etiológicos.

Um endofenótipo (ou fenótipo intermédio) é essencialmente um biomarcador que pode ser neurofisiológico, neuropsicológico, cognitivo, neuroanatómico, bioquímico, endocrinológico, etc. Para um marcador ser considerado um endofenótipo para uma dada doença (ou, no geral, para qualquer fenótipo complexo) ele deve idealmente observar todos os seguintes critérios: (1) estar associado à doença na população, (2) co-segregar com a doença nas famílias, (3) ser hereditário (i.e. a sua presença num indivíduo ser positivamente correlacionada com o seu grau de parentesco aos indivíduos portadores do endofenótipo) (Figura 3), (4) ser independente do estado (i.e. manifestar-se num indivíduo quer a doença esteja ou não presente) e (5) expressar-se em membros da família não afectados numa taxa maior do que na população geral (Gottesman et al., 2003). Quando não existe ainda evidência da observação de todos os 
critérios, nomeadamente da hereditariedade o fenótipo é antes descrito como 'fenótipo intermédio'.

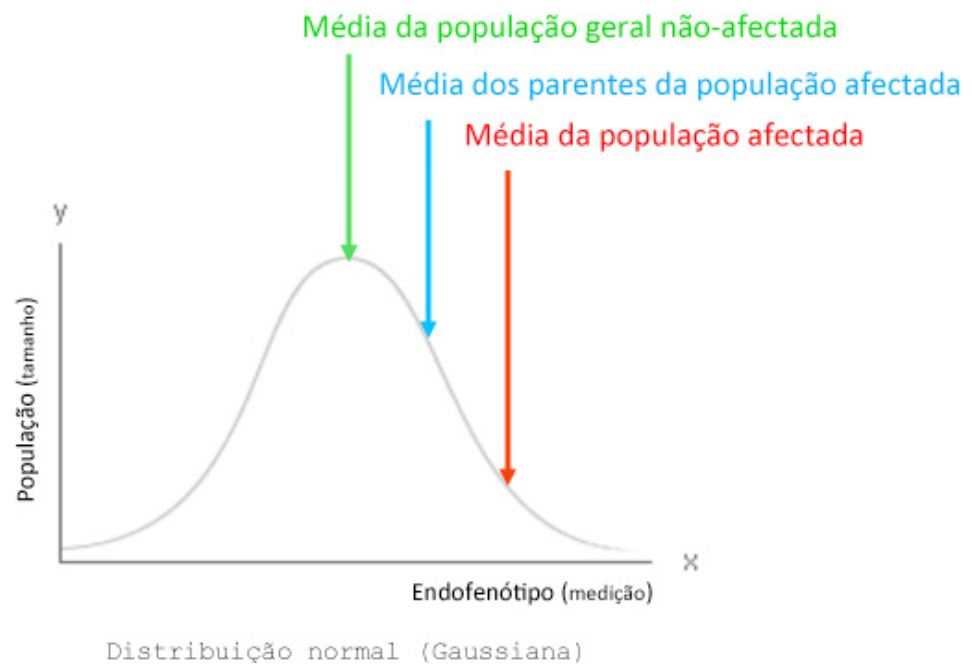

Figura 3. Na medição de um dado endofenótipo, espera-se que os parentes não afectados de indivíduos afectados se situem em média entre os indivíduos afectados e a população geral não afectada.

A hipótese subjacente nos estudos de endofenótipos é a de que os endofenótipos têm uma etiologia putativamente mais simples e portanto podem ser mais fáceis de mapear geneticamente do que os fenótipos comportamentais complexos (como as doenças psiquiátricas). Se assim for, espera-se que o número de variações genéticas com impacto nessas características seja menor do que o das envolvidas na produção do fenótipo complexo e daí, que cada uma tenha um impacto maior. Isto significa uma maior penetrância (i.e. magnitude do impacto) alélica nos endofenótipos e portanto um poder estatístico acrescido. Daqui decorre que os genes para a susceptibilidade da esquizofrenia devem mostrar associações com aspectos anormais da estrutura/função do cérebro por sua vez associados à esquizofrenia, até mesmo em indivíduos normais (Tan, Callicott, \& Weinberger, 2008). Tal foi verificado com a COMT 
(Malhotra et al., 2002; Bruder et al., 2005) e vários outros genes (Meyer-Lindenberg \& Weinberger, 2006). Também parece existir maior linkage para as características endofenótipicas do que para os diagnósticos clínicos como a esquizofrenia (Paunio et al., 2004). Tal abordagem conduzirá por último a uma melhor visualização da cadeia fisiopatológica inerente à esquizofrenia, o que é obviamente útil para o desenvolvimento de novos tratamentos. Também permite o escrutínio de hipóteses sobre a ação de genes de risco ou a descoberta de novos genes de risco, através, por exemplo, de estudos GWA de endofenótipos, que decorrem atualmente.

Exemplos de endofenótipos clássicos há muito conhecidos associados à esquizofrenia são: aumento do tempo de reação (De Amicis, Wagstaff, \& Cromwell, 1986), défice de atenção avaliado pelo teste de performance contínua (TPC) (Cornblatt \& Keilp, 1994) e alargamento ventricular (Shihabuddin et al., 1996). Alguns endofenótipos clássicos da esquizofrenia, mais do que serem herdáveis, têm de facto sido mapeados a regiões genómicas de risco para a esquizofrenia através de estudos linkage ou a polimorfismos genéticos específicos mediante estudos de associação genética. Por exemplo, a alteração dos movimentos de perseguição ocular ('eye-trackingdysfunction', ETD), também designada intrusão de movimentos sacádicos nos movimentos de perseguição ocular lenta ('smooth-pursuiteyemovements', SPEM) tem sido associada ao cromossoma $6 \mathrm{p} 21$ (Arolt et al., 1996; Ross, 2003). A fraca supressão dos potenciais evocados P50 ('event-relatedpotentials', ERP), avaliada com electroencefalografia (EEG), e que indicia um défice de 'seleção' ('gating') sensorial auditiva (Siegel, Waldo, Mizner, Adler, \& Freedman, 1984), foi mapeada no gene do receptor (CHRNA7) (Freedman et al., 1997). A diminuição da amplitude do potencial evocado auditivo P300, que sugere um desajuste do processamento controlado de informação (Sham et al., 1994), tem sido associada à presença do alelo Met158 do polimorfismo COMT Val158Met, particularmente em doentes esquizofrénicos (Gallinat et al., 2003). Finalmente, outro endofenótipo da esquizofrenia, a perda da inibição pré-pulsiva ('prepulseinbibition', PPI) da resposta de sobressalto que se julga refletir problemas nos mecanismos inibidores usados no gatingmoto-sensorial (Braff, Grillon, \& Geyer, 1992) mostrou ser regulado pela dopamina em 
modelos animais (Geyer, Krebs-Thomson, Braff, \& Swerdlow, 2001), o que é consistente com a hipótese da dopamina da esquizofrenia.

A imagiologia genética é uma área de investigação recente que usa a genética molecular ou quantitativa em conjunto com a imagiologia. É um exemplo de uma abordagem endofenotípica, em que os endofenótipos são imagiológicos. Em adição aos exemplos de imagiologia genética enunciados acima (ex., a electrofisiológica como o EEG), outros estudos com imagiologia de ressonância magnética funcional ('functionalmagneticressonanceimaging', fMRI), serão posteriormente abordados em maior detalhe neste livro. Ao avaliar o modo como variações genéticas de risco para a esquizofrenia influenciam a estrutura e a função cerebrais, espera-se que a imagiologia genética possa ter impacto no contexto clínico melhorando (1) a detecção precoce e mais específica de indivíduos de alto risco (quer para a esquizofrenia quer para desajustes comportamentais dentro ou fora do contexto da esquizofrenia), (2) a caraterização da fisiopatologia inerente à doença e (3) a previsão da resposta a tratamentos farmacológicos e psicoterapêuticos.

\section{Referências bibliográficas}

ABI-DARgham, A. (2004). Do we still believe in the dopamine hypothesis? New data bring new evidence. Int.J Neuropsychopharmacol., 7 Suppl 1, S1-S5.

Abi-Dargham, A., Gil, R., Krystal, J., BAldwin, R. M., Seibyl, J. P., Bowers, M. et al. (1998). Increased striatal dopamine transmission in schizophrenia: confirmation in a second cohort. Am J Psychiatry, 155, 761-767.

abi-Dargham, A., Mawlawi, O., lombardo, I., Gil, R., Martinez, D., HuAng, Y. et al. (2002). Prefrontal dopamine D1 receptors and working memory in schizophrenia. J.Neurosci., 22, 3708-3719.

Abi-DArgham, A. \& MOORE, H. (2003). Prefrontal DA transmission at D1 receptors and the pathology of schizophrenia. Neuroscientist., 9, 404-416.

AKil, M., Kolachana, B. S., Rothmond, D. A., Hyde, T. M., Weinberger, D. R., \& KLEINMAN, J. E. (2003). Catechol-O-methyltransferase genotype and dopamine regulation in the human brain. J.Neurosci., 23, 2008-2013.

AKil, M., Pierri, J. N., Whitehead, R. E., Edgar, C. L., Mohila, C., SAmpson, A. R. et al. (1999). Lamina-specific alterations in the dopamine innervation of the prefrontal cortex in schizophrenic subjects. Am.J.Psychiatry, 156, 1580-1589.

Allen, N. C., BAgAde, S., TAnzI, R., \& BerTram, L. (2008). The SchizophreniaGene. Database. Schizophrenia Research Forum. http://www.schizophreniaforum.org/res/sczgene/ default.asp. Ref Type: Generic 
ANGrist, B., ROtrosen, J., \& GERShON, S. (1980). Differential effects of amphetamine and neuroleptics on negative vs. positive symptoms in schizophrenia. Psychopharmacology (Berl), 72, 17-19.

ANGrist, B., Rotrosen, J., \& Gershon, S. (2001). Commentary on: "Differential effects of amphetamine and neuroleptics on negative vs. positive symptoms in schizophrenia." Psychopharmacology (1980) 72:17-19. Psychopharmacology, 158, 219-221.

ANGRIST, B. M., SHOPSIN, B., \& GERSHON, S. (1971). Comparative psychotomimetic effects of stereoisomers of amphetamine. Nature, 234, 152-153.

Arolt, V., Lencer, R., Nolte, A., Muller-Myhsok, B., Purmann, S., SChurmann, M. et al. (1996). Eye tracking dysfunction is a putative phenotypic susceptibility marker of schizophrenia and maps to a locus on chromosome $6 \mathrm{p}$ in families with multiple occurrence of the disease. Am J Med Genet, 67, 564-579.

ARranZ, M. J. \& KAPUR, S. (2008). Pharmacogenetics in Psychiatry: Are We Ready for Widespread Clinical Use? Schizophrenia Bulletin, 34, 1130-1144.

arseneault, L., Cannon, M., Poulton, R., Murray, R., Caspi, A., \& MoffitT, T. E. (2002). Cannabis use in adolescence and risk for adult psychosis: longitudinal prospective study. BMJ, 325, 1212-1213.

BADNER, J. A. \& GERSHON, E. S. (2002). Meta-analysis of whole-genome linkage scans of bipolar disorder and schizophrenia. Mol.Psychiatry, 7, 405-411.

Bebiington, P., Wilkins, S., JONes, P., FOerster, A., Murray, R., TOONE, B. et al. (1993). Life events and psychosis. Initial results from the Camberwell Collaborative Psychosis Study. Br.J Psychiatry, 162, 72-79.

BERRETTINI, W. (2003). Bipolar disorder and schizophrenia: not so distant relatives? World Psychiatry, 2, 68-72.

Bertolino, A., Breier, A., CAllicott, J. H., Adler, C., Mattay, V. S., Shapiro, M. et al. (2000). The relationship between dorsolateral prefrontal neuronal $\mathrm{N}$-acetylaspartate and evoked release of striatal dopamine in schizophrenia. Neuropsychopharmacology, 22, 125-132.

Bilder, R. M., Goldman, R. S., Volavka, J., CZObor, P., Hoptman, M., Sheitman, B. et al. (2002). Neurocognitive Effects of Clozapine, Olanzapine, Risperidone, and Haloperidol in Patients with Chronic Schizophrenia or Schizoaffective Disorder. Am J Psychiatry, 159, 1018-1028.

BOYDELL, J., VAN, O. J., MCKENZIE, K., \& MURRAY, R. M. (2004). The association of inequality with the incidence of schizophrenia - an ecological study. Soc.Psychiatry Psychiatr. Epidemiol., 39, 597-599.

BRAFF, D. L., GRILlON, C., \& GEYER, M. A. (1992). Gating and habituation of the startle reflex in schizophrenic patients. Arch Gen Psychiatry, 49, 206-215.

Breen, G., Prata, D., Osborne, S., Munro, J., SinClair, M., LI, T. et al. (2006). Association of the dysbindin gene with bipolar affective disorder. Am J Psychiatry, 163, 1636-1638.

Breier, A., SU, T. P., SAUnders, R., Carson, R. E., Kolachana, B. S., DE, B. A. et al. (1997). Schizophrenia is associated with elevated amphetamine-induced synaptic dopamine concentrations: evidence from a novel positron emission tomography method. Proc. Natl.Acad.Sci.U.S.A, 94, 2569-2574.

BROMET, E. J. \& FENNIG, S. (1999). Epidemiology and natural history of schizophrenia. Biological Psychiatry, 46, 871-881.

Brown, G. W. \& BIRLEY, J. L. (1968). Crises and life changes and the onset of schizophrenia. J Health Soc.Behav., 9, 203-214. 
Brozoski, T. J., Brown, R. M., Rosvold, H. E., \& Goldman, P. S. (1979). Cognitive deficit caused by regional depletion of dopamine in prefrontal cortex of rhesus monkey. Science, 205, 929-932.

Bruder, G. E., KeilP, J. G., XU, H., Shikhman, M., SChORI, E., Gorman, J. M. et al. (2005). Catechol-O-Methyltransferase (COMT) Genotypes and Working Memory: Associations with Differing Cognitive Operations. Biological Psychiatry, 58, 901-907.

CAnnon, T. D., Kaprio, J., LONnQVist, J., HutTunen, M., \& KoskenvuO, M. (1998). The genetic epidemiology of schizophrenia in a Finnish twin cohort. A population-based modeling study. Arch.Gen.Psychiatry, 55, 67-74.

CAPuAno, B., Crosby, I. T., \& Lloyd, E. J. (2002). Schizophrenia: genesis, receptorology and current therapeutics. Curr.Med Chem., 9, 521-548.

CARDNO, A. G. \& GOTTESMAN, I. I. (2000). Twin studies of schizophrenia: from bow-andarrow concordances to star wars Mx and functional genomics. Am.J.Med.Genet., 97, 12-17.

CARDno, A. G., MARShall, E. J., CoID, B., Macdonald, A. M., Ribchester, T. R., Davies, N. J. et al. (1999). Heritability estimates for psychotic disorders: the Maudsley twin psychosis series. Arch.Gen.Psychiatry, 56, 162-168.

CARLSSON, A. (1978). Antipsychotic drugs, neurotransmitters, and schizophrenia. Am J Psychiatry, 135, 165-173.

CARR, D. B. \& SESACK, S. R. (2000). Projections from the Rat Prefrontal Cortex to the Ventral Tegmental Area: Target Specificity in the Synaptic Associations with Mesoaccumbens and Mesocortical Neurons. Journal of Neuroscience, 20, 3864-3873.

Caspi, A., MoffitT, T. E., CANnON, M., MCClay, J., Murray, R., Harrington, H. et al. (2005). Moderation of the effect of adolescent-onset cannabis use on adult psychosis by a functional polymorphism in the catechol-O-methyltransferase gene: longitudinal evidence of a gene $\mathrm{X}$ environment interaction. Biol.Psychiatry, 57, 1117-1127.

Cha, J. H., Kosinski, C. M., Kerner, J. A., Alsdorf, S. A., Mangiarini, L., Davies, S. W. et al. (1998). Altered brain neurotransmitter receptors in transgenic mice expressing a portion of an abnormal human huntington disease gene. Proc.Natl.Acad.Sci.U.S.A, 95, 6480-6485.

Chowdari, K. V., Mirnics, K., Semwal, P., Wood, J., Lawrence, E., Bhatia, T. et al. (2002). Association and linkage analyses of RGS4 polymorphisms in schizophrenia. Hum.Mol. Genet, 11, 1373-1380.

Christie, M. J., Bridge, S., JAMES, L. B., \& BEART, P. M. (1985). Excitotoxin lesions suggest an aspartatergic projection from rat medial prefrontal cortex to ventral tegmental area. Brain Research, 333, 169-172.

Chumakov, I., Blumenfeld, M., Guerassimenko, O., Cavarec, L., Palicio, M., AbderRAHIM, H. et al. (2002). Genetic and physiological data implicating the new human gene G72 and the gene for D-amino acid oxidase in schizophrenia. Proc.Natl.Acad.Sci.U.S.A, 99, 13675-13680.

Clarke, M. C., Harley, M., \& CANNON, M. (2006). The Role of Obstetric Events in Schizophrenia. Schizophr Bull, 32, 3-8.

Collier, D. A., Arranz, M. J., Sham, P., Battersby, S., Vallada, H., Gill, P. et al. (1996). The serotonin transporter is a potential susceptibility factor for bipolar affective disorder. Neuroreport, 7, 1675-1679.

Comings, D. E., Comings, B. G., Muhleman, D., Dietz, G., Shahbahrami, B., Tast, D. et al. (1991). The dopamine D2 receptor locus as a modifying gene in neuropsychiatric disorders. JAMA, 266, 1793-1800. 
CORnBlatT, B. A. \& KeIlP, J. G. (1994). Impaired attention, genetics, and the pathophysiology of schizophrenia. Schizophr Bull, 20, 31-46.

Coron, B., CAmpion, D., Thibaut, F., Dollfus, S., Preterre, P., LANGlois, S. et al. (1996). Association study between schizophrenia and monoamine oxidase A and B DNA polymorphisms. Psychiatry Res, 62, 221-226.

CRADDOCK, N. \& OWEN, M. J. (2005). The beginning of the end for the Kraepelinian dichotomy. Br.J Psychiatry, 186, 364-366.

CREeSE, I., BURT, D. R., \& SNYDER, S. H. (1976). Dopamine receptor binding predicts clinical and pharmacological potencies of antischizophrenic drugs. Science, 192, 481-483.

Daniels, J. K., Williams, N. M., Williams, J., Jones, L. A., CARDNO, A. G., MurPhy, K. C. et al. (1996). No evidence for allelic association between schizophrenia and a polymorphism determining high or low catechol O-methyltransferase activity. Am J Psychiatry, $153,268-270$.

DAVidson, M., KeEFE, R. S., MOHS, R. C., SIEVER, L. J., Losonczy, M. F., HorvaTH, T. B. et al. (1987). L-dopa challenge and relapse in schizophrenia. Am J Psychiatry, 144, 934-938.

DAVIS, K. L., KAHN, R. S., KO, G., \& DAVIDSON, M. (1991). Dopamine in schizophrenia: a review and reconceptualization. Am J Psychiatry, 148, 1474-1486.

De Amicis, L. A., WAgstafF, D. A., \& Cromwell, R. L. (1986). Reaction time crossover as a marker of schizophrenia and of higher functioning. J Nerv.Ment.Dis., 174, 177-179.

DELISI, L. E. \& FLEISCHHAKER, W. (2007). Schizophrenia research in the era of the genome, 2007. Curr.Opin.Psychiatry, 20, 109-110.

Francks, C., Delisi, L. E., Shaw, S. H., Fisher, S. E., Richardson, A. J., STEIN, J. F. et al. (2003). Parent-of-origin effects on handedness and schizophrenia susceptibility on chromosome 2p12-q11. Hum.Mol.Genet, 12, 3225-3230.

FREEDMAN, R. (2003). Schizophrenia. N.Engl.J Med, 349, 1738-1749.

Freedman, R., CoOn, H., Myles-Worsley, M., OrR-Urtreger, A., Olincy, A., DaVis, A. et al. (1997). Linkage of a neurophysiological deficit in schizophrenia to a chromosome 15 locus. Proc.Natl.Acad.Sci.U.S.A, 94, 587-592.

Gallinat, J., Bajbouj, M., SANDer, T., SChlattmann, P., XU, K., Ferro, E. F. et al. (2003). Association of the G1947A COMT (Val(108/158)Met) gene polymorphism with prefrontal P300 during information processing. Biol.Psychiatry, 54, 40-48.

Geyer, M. A., Krebs-Thomson, K., BrAFF, D. L., \& SWERdlow, N. R. (2001). Pharmacological studies of prepulse inhibition models of sensorimotor gating deficits in schizophrenia: a decade in review. Psychopharmacology (Berl), 156, 117-154.

Gogos, J. A., Morgan, M., Luine, V., SAntha, M., Ogawa, S., Pfaff, D. et al. (1998). Catechol-O-methyltransferase-deficient mice exhibit sexually dimorphic changes in catecholamine levels and behavior. Proc.Natl.Acad.Sci.U.S.A, 95, 9991-9996.

Gotham, A. M., Brown, R. G., \& MARSDen, C. D. (1988). 'Frontal' cognitive function in patients with Parkinson's disease 'on' and 'off' levodopa. Brain, 111 (Pt 2), 299-321.

GOTTESMAN, I. I. (1991). Schizophrenia Genesis: The Origins of Madness.

GOTTESman, I. I. \& GOULD, T. D. (2003). The endophenotype concept in psychiatry: etymology and strategic intentions. Am.J.Psychiatry, 160, 636-645.

GRACE, A. A. (2000). Gating of information flow within the limbic system and the pathophysiology of schizophrenia. Brain Res. Rev., 31, 330-341.

Hagger, C., Buckley, P., KenNy, J. T., Friedman, L., Ubogy, D., \& Meltzer, H. Y. (1993). Improvement in cognitive functions and psychiatric symptoms in treatment-refractory schizophrenic patients receiving clozapine. Biol.Psychiatry, 34, 702-712. 
Hawton, K., SutTon, L., Haw, C., Sinclair, J., \& DeEKs, J. J. (2005). Schizophrenia and suicide: systematic review of risk factors. Br.J Psychiatry, 187, 9-20.

henquet, C., Krabbendam, L., Spauwen, J., Kaplan, C., Lieb, R., WitTchen, H. U. et al. (2005). Prospective cohort study of cannabis use, predisposition for psychosis and psychotic symptoms in young people. BMJ, 330, 11.

henquet, C., Rosa, A., Krabbendam, L., Papiol, S., Fananas, L., DrukKer, M. et al. (2006). An experimental study of catechol-o-methyltransferase Val158Met moderation of delta-9-tetrahydrocannabinol-induced effects on psychosis and cognition. Neuropsychopharmacology, 31, 2748-2757.

Hodgins, S. \& MUlLER-ISBERneR, R. (2004). Preventing crime by people with schizophrenic disorders: the role of psychiatric services. Br.J Psychiatry, 185, 245-250.

Honey, G. D., Bullmore, E. T., SONI, W., VARATheESAN, M., Williams, S. C. R., \& Sharma, T. (1999). Differences in frontal cortical activation by a working memory task after substitution of risperidone for typical antipsychotic drugs in patients with schizophrenia. Proceedings of the National Academy of Sciences, 96, 13432-13437.

howes, O. D., Montgomery, A. J., Asselin, M. C., Murray, R. M., Grasby, P. M., \& MCGUIRE, P. K. (2007). Molecular imaging studies of the striatal dopaminergic system in psychosis and predictions for the prodromal phase of psychosis. Br.J Psychiatry Suppl, 51, s13-s18.

huotari, M., Gogos, J. A., Karayiorgou, M., Koponen, O., Forsberg, M., RaAsmaja, A. et al. (2002). Brain catecholamine metabolism in catechol-O-methyltransferase (COMT)deficient mice. Eur.J.Neurosci., 15, 246-256.

IVERSEN, S. D. \& IVERSEN, L. L. (2007). Dopamine: 50 years in perspective. Trends Neurosci., 30, 188-193.

Jackson, M. E., Frost, A. S., \& Moghaddam, B. (2001). Stimulation of prefrontal cortex at physiologically relevant frequencies inhibits dopamine release in the nucleus accumbens. Journal of Neurochemistry, 78, 920-923.

JAVITT, D. C. (2001). Management of negative symptoms of schizophrenia. Curr.Psychiatry Rep., 3, 413-417.

Jimerson, D. C., Cutler, N. R., Post, R. M., Rey, A., Gold, P. W., Brown, G. M. et al. (1984). Neuroendocrine responses to apomorphine in depressed patients and healthy control subjects. Psychiatry Res., 13, 1-12.

KAPUR, S. (2003). Psychosis as a state of aberrant salience: a framework linking biology, phenomenology, and pharmacology in schizophrenia. Am.J.Psychiatry, 160, 13-23.

KAPUR, S. \& MAMO, D. (2003). Half a century of antipsychotics and still a central role for dopamine D2 receptors. Prog.Neuropsychopharmacol.Biol.Psychiatry, 27, 1081-1090.

Kegeles, L. S., Bi-DARgham, A., ZeA-Ponce, Y., Rodenhiser-Hill, J., MANN, J. J., VAN HEERTUM, R. L. et al. (2000). Modulation of amphetamine-induced striatal dopamine release by ketamine in humans: implications for schizophrenia. Biological Psychiatry, $48,627-640$.

Kendler, K. S., GRUenberg, A. M., \& Kinney, D. K. (1994). Independent diagnoses of adoptees and relatives as defined by DSM-III in the provincial and national samples of the Danish Adoption Study of Schizophrenia. Arch.Gen.Psychiatry, 51, 456-468.

Khromova, I., RAuhala, P., Zolotov, N., \& MANnisto, P. T. (1995). Tolcapone, an inhibitor of catechol O-methyltransferase, counteracts memory deficits caused by bilateral cholinotoxin lesions of the basal nuclei of Meynert. Neuroreport, 6, 1219-1222.

KNAPP, M., MANGALORE, R., \& SIMON, J. (2004). The global costs of schizophrenia. Schizophr Bull, 30, 279-293. 
Kraepelin, E. (1896). Textbook of Psychiatry. (5 $5^{\text {th }}$ ed.).

Krystal, J. H., Karper, L. P., Seibyl, J. P., Freeman, G. K., Delaney, R., Bremner, J. D. et al. (1994). Subanesthetic effects of the noncompetitive NMDA antagonist, ketamine, in humans. Psychotomimetic, perceptual, cognitive, and neuroendocrine responses. Arch Gen Psychiatry, 51, 199-214.

KUROKI, T., KAWAHARA, T., YONEZAWA, Y., \& TASHIRO, N. (1999). Effects of the serotonin2A/2C receptor agonist and antagonist on phencyclidine-induced dopamine release in rat medial prefrontal cortex. Prog.Neuropsychopharmacol.Biol.Psychiatry, 23, 1259-1275.

LANG, U. E., Puls, I., Muller, D. J., STRutz-Seebohm, N., \& GAllinat, J. (2007). Molecular mechanisms of schizophrenia. Cell Physiol Biochem., 20, 687-702.

LARuelle, M. \& ABi-Dargham, A. (1999). Dopamine as the wind of the psychotic fire: new evidence from brain imaging studies. J Psychopharmacol., 13, 358-371.

LARUelle, M., ABI-DARghaM, A., GIL, R., Kegeles, L., \& INNIS, R. (1999). Increased dopamine transmission in schizophrenia: relationship to illness phases. Biol.Psychiatry, 46, 56-72.

Laruelle, M., Abi-DArgham, A., van DyCK, C. H., Gil, R., D'SouzA, C. D., Erdos, J. et al. (1996). Single photon emission computerized tomography imaging of amphetamineinduced dopamine release in drug-free schizophrenic subjects. Proc.Natl.Acad.Sci.U.S.A, 93, 9235-9240.

LEAN, M. E. \& PAJONK, F. G. (2003). Patients on atypical antipsychotic drugs: another highrisk group for type 2 diabetes. Diabetes Care, 26, 1597-1605.

LeWis, C. M., Levinson, D. F., Wise, L. H., Delisi, L. E., STraub, R. E., HovatTA, I. et al. (2003). Genome scan meta-analysis of schizophrenia and bipolar disorder, part II: Schizophrenia. Am.J.Hum.Genet., 73, 34-48.

LEWIS, D. A. \& Lieberman, J. A. (2000). Catching Up on Schizophrenia: Natural History and Neurobiology. Neuron, 28, 325-334.

LI, D., COllier, D. A., \& HE, L. (2006). Meta-analysis shows strong positive association of the neuregulin 1 (NRG1) gene with schizophrenia. Hum.Mol.Genet, 15, 1995-2002.

LI, T., YANG, L., Wiese, C., XU, C. T., ZENG, Z., GIROS, B. et al. (1994). No association between alleles or genotypes at the dopamine transporter gene and schizophrenia. Psychiatry Res., 52, 17-23.

Lieberman, J. A., Stroup, T. S., MCEvoy, J. P., Swartz, M. S., Rosenheck, R. A., PERKins, D. O. et al. (2005). Effectiveness of Antipsychotic Drugs in Patients with Chronic Schizophrenia. The New England Journal of Medicine, 353, 1209-1223.

Liljequist, R., HAAPAlinna, A., Ahlander, M., LI, Y. H., \& MANnisTO, P. T. (1997). Catechol O-methyltransferase inhibitor tolcapone has minor influence on performance in experimental memory models in rats. Behav.Brain Res., 82, 195-202.

liu, H., Heath, S. C., Sobin, C., Roos, J. L., Galke, B. L., Blundell, M. L. et al. (2002). Genetic variation at the 22q11 PRODH2/DGCR6 locus presents an unusual pattern and increases susceptibility to schizophrenia. Proceedings of the National Academy of Sciences, 99, 3717-3722.

malhotra, A. K., Kestler, L. J., Mazzanti, C., BATes, J. A., Goldberg, T., \& Goldman, D. (2002). A functional polymorphism in the COMT gene and performance on a test of prefrontal cognition. Am.J.Psychiatry, 159, 652-654.

MCGUe, M., GOTTESMAN, I. I., \& RAO, D. C. (1983). The transmission of schizophrenia under a multifactorial threshold model. Am J Hum.Genet, 35, 1161-1178.

MELTZER, H. Y. \& MCGURK, S. R. (1999). The effects of clozapine, risperidone, and olanzapine on cognitive function in schizophrenia. Schizophr.Bull., 25, 233-255. 
MeYer-Lindenberg, A., Kohn, P. D., Kolachana, B., Kippenhan, S., Inerney-LeO, A., NUSSBAUM, R. et al. (2005). Midbrain dopamine and prefrontal function in humans: interaction and modulation by COMT genotype. Nat.Neurosci., 8, 594-596.

Meyer-Lindenberg, A., Miletich, R. S., KOHN, P. D., EsPosito, G., CARson, R. E., QUARANTELLI, M. et al. (2002). Reduced prefrontal activity predicts exaggerated striatal dopaminergic function in schizophrenia. Nat.Neurosci., 5, 267-271.

MEYER-LindenBERG, A. \& WEINBERGER, D. R. (2006). Intermediate phenotypes and genetic mechanisms of psychiatric disorders. Nat.Rev.Neurosci., 7, 818-827.

MOGHADDAM, B. \& BUNNEY, B. S. (1990). Acute effects of typical and atyphical antipsychotic drugs on the release of dopamine from prefrontal cortex, nucleus accumbens, and striatum of the rat: an in vivo microdialysis study. J.Neurochem., 54, 1755-1760.

Moore, T. H., ZAmmit, S., Lingford-Hughes, A., BARnes, T. R., JOneS, P. B., BurKe, M. et al. (2007). Cannabis use and risk of psychotic or affective mental health outcomes: a systematic review. Lancet, 370, 319-328.

Moriarty, P. J., Lieber, D., BennetT, A., White, L., PARrella, M., HARvey, P. D. et al. (2001). Gender Differences in Poor Outcome Patients With Lifelong Schizophrenia. Schizophrenia Bulletin, 27, 103-113.

Morrison, P. D., Zois, V., MCKeown, D. A., LeE, T. D., Holt, D. W., Powell, J. F. et al. (2009). The acute effects of synthetic intravenous Delta9-tetrahydrocannabinol on psychosis, mood and cognitive functioning. Psychol.Med., 39, 1607-1616.

MunAfo, M. R., ATTwood, A. S., \& Flint, J. (2008). Neuregulin 1 genotype and schizophrenia. Schizophr Bull, 34, 9-12.

Murray, R. M., O'Callaghan, E., CAStle, D. J., \& LeWis, S. W. (1992). A neurodevelopmental approach to the classification of schizophrenia. Schizophr Bull, 18, 319-332.

Mutsuddi, M., Morris, D. W., Waggoner, S. G., DAly, M. J., SCOlnick, E. M., \& SKlar, P. (2006). Analysis of high-resolution HapMap of DTNBP1 (Dysbindin) suggests no consistency between reported common variant associations and schizophrenia. Am J Hum.Genet, 79, 903-909.

O’donovan, M. C., Craddock, N., Norton, N., Williams, H., Peirce, T., Moskvina, V. et al. (2008). Identification of loci associated with schizophrenia by genome-wide association and follow-up. Nat Genet, 40, 1053-1055.

OKubo, Y., Suhara, T., Suzuki, K., KobayAshi, K., InOUE, O., TERASAKi, O. et al. (1997). Decreased prefrontal dopamine D1 receptors in schizophrenia revealed by PET. Nature, 385, 634-636.

OWEn, M. J., CRADDOCK, N., \& JABlensky, A. (2007). The genetic deconstruction of psychosis. Schizophr.Bull., 33, 905-911.

Patil, S. T., Zhang, L., MARTenyi, F., LOWE, S. L., JACKson, K. A., Andreev, B. V. et al. (2007). Activation of mGlu2/3 receptors as a new approach to treat schizophrenia: a randomized Phase 2 clinical trial. Nat.Med., 13, 1102-1107.

Paunio, T., Tuulio-Henriksson, A., hiekkalinna, T., Perola, M., Varilo, T., Partonen, T. et al. (2004). Search for cognitive trait components of schizophrenia reveals a locus for verbal learning and memory on $4 \mathrm{q}$ and for visual working memory on $2 \mathrm{q}$. Hum. Mol.Genet., 13, 1693-1702.

PeARson, T. A. \& MANOlio, T. A. (2008). How to Interpret a Genome-wide Association Study. JAMA: The Journal of the American Medical Association, 299, 1335-1344.

PicChioni, M. M. \& MURRAY, R. M. (2007). Schizophrenia. BMJ, 335, 91-95.

Prata, D., Breen, G., Osborne, S., Munro, J., ST, C. D., \& Collier, D. (2007). Association of DAO and G72(DAOA)/G30 genes with bipolar affective disorder. Am J Med Genet B Neuropsychiatr.Genet. 
Prata, D. P., Breen, G., Munro, J., Sinclair, M., Osborne, S., Li, T. et al. (2006). Bipolar 1 disorder is not associated with the RGS4, PRODH, COMT and GRK3 genes. Psychiatr. Genet, 16, 229-230.

REYNOLDS, G. P. \& HARTE, M. K. (2007). The neuronal pathology of schizophrenia: molecules and mechanisms. Biochem.Soc.Trans., 35, 433-436.

Robinson, D. G., Woerner, M. G., Delman, H. M., \& KAnE, J. M. (2005). Pharmacological Treatments for First-Episode Schizophrenia. Schizophrenia Bulletin, 31, 705-722.

Ross, R. G. (2003). Early expression of a pathophysiological feature of schizophrenia: saccadic intrusions into smooth-pursuit eye movements in school-age children vulnerable to schizophrenia. J Am Acad.Child Adolesc.Psychiatry, 42, 468-476.

RUTTER, M. (2006). Genes and Behavior: Nature-Nurture Interplay Explained. Blackwell Publishing Ltd.

SAHA, S., CHANT, D., WELHAM, J., \& MCGRATH, J. (2005). A systematic review of the prevalence of schizophrenia. PLoS.Med., 2, e141.

SAHA, S., WElham, J., CHANT, D., \& MCGRATH, J. (2006). Incidence of schizophrenia does not vary with economic status of the country: evidence from a systematic review. Soc. Psychiatry Psychiatr.Epidemiol., 41, 338-340.

SASAKI, T., DAI, X. Y., KuwatA, S., FukudA, R., Kunugi, H., HATTORI, M. et al. (1997). Brain-derived neurotrophic factor gene and schizophrenia in Japanese subjects. Am J Med Genet, 74, 443-444.

SAWAGUCHI, T. \& GOLDMAN-RAKIC, P. S. (1994). The role of D1-dopamine receptor in working memory: local injections of dopamine antagonists into the prefrontal cortex of rhesus monkeys performing an oculomotor delayed-response task. J.Neurophysiol., 71, 515-528.

SCHMIDT-KASTNER, R., VAN, O. J., STEINBUSCH, W. M., \& SCHMiTZ, C. (2006). Gene regulation by hypoxia and the neurodevelopmental origin of schizophrenia. Schizophr Res., $84,253-271$.

Schultz, S. H., NORTh, S. W., \& Shields, C. G. (2007). Schizophrenia: a review. Am Fam. Physician, 75, 1821-1829.

SeEman, P., Chau-Wong, M., Tedesco, J., \& WONG, K. (1975). Brain receptors for antipsychotic drugs and dopamine: direct binding assays. Proc.Natl.Acad.Sci.U.S.A, 72, 4376-4380.

SEEMAN, P. \& KAPUR, S. (2000). Schizophrenia: more dopamine, more D2 receptors. Proc. Natl.Acad.Sci.U.S.A, 97, 7673-7675.

SEEMAN, P., WEINSHENKER, D., QUIRION, R., SRIVASTAVA, L. K., BHARDWAJ, S. K., GRANDY, D. K. et al. (2005). Dopamine supersensitivity correlates with D2High states, implying many paths to psychosis. Proc.Natl.Acad.Sci.U.S.A, 102, 3513-3518.

SESACK, S. R. \& CARR, D. B. (2002). Selective prefrontal cortex inputs to dopamine cells: implications for schizophrenia. Physiology \& Behavior, 77, 513-517.

Sham, P. C., MOrTon, N. E., Muir, W. J., WAlker, M., Collins, A., Shields, D. C. et al. (1994). Segregation analysis of complex phenotypes: an application to schizophrenia and auditory P300 latency. Psychiatr.Genet, 4, 29-38.

Shihabuddin, L., Silverman, J. M., Buchsbaum, M. S., Seiver, L. J., LUU, C., Germans, M. K. et al. (1996). Ventricular enlargement associated with linkage marker for schizophrenia-related disorders in one pedigree. Mol.Psychiatry, 1, 215-222.

SIEGEl, C., WAldo, M., MiZner, G., Adler, L. E., \& FreEdman, R. (1984). Deficits in sensory gating in schizophrenic patients and their relatives. Evidence obtained with auditory evoked responses. Arch Gen Psychiatry, 41, 607-612. 
Steen, R. G., Mull, C., MCClure, R., HAMER, R. M., \& Lieberman, J. A. (2006). Brain volume in first-episode schizophrenia: systematic review and meta-analysis of magnetic resonance imaging studies. Br.J Psychiatry, 188, 510-518.

STEFANSSON, H., SigurdsSON, E., STEINTHORSDOTTIR, V., BJORNSDOTTIR, S., SIGMUNDSSON, T., GHOSH, S. et al. (2002). Neuregulin 1 and susceptibility to schizophrenia. Am J Hum. Genet, 71, 877-892.

Stefansson, H., Rujescu, D., Cichon, S., Pietilainen, O. P. H., Ingason, A., SteinberG, S. et al. (2008). Large recurrent microdeletions associated with schizophrenia. Nature, $455,232-236$.

STraub, R. E., JiAng, Y., MACLEAN, C. J., MA, Y., WEBB, B. T., MYAKISHEV, M. V. et al. (2002). Genetic variation in the 6p22.3 gene DTNBP1, the human ortholog of the mouse dysbindin gene, is associated with schizophrenia. Am J Hum.Genet, 71, 337-348.

TAlKowski, M. E., BAMne, M., MANSOUR, H., \& NimgaOnKAR, V. L. (2007). Dopamine genes and schizophrenia: case closed or evidence pending? Schizophr Bull, 33, 1071-1081.

TAmminga, C. A., BuChanAn, R. W., \& GOLD, J. M. (1998). The role of negative symptoms and cognitive dysfunction in schizophrenia outcome. Int.Clin.Psychopharmacol., 13 Suppl 3, S21-S26.

TAN, H. Y., CAllicotT, J. H., \& WeinberGer, D. R. (2008). Intermediate phenotypes in schizophrenia genetics redux: is it a no brainer? Mol.Psychiatry, 13, 233-238.

Thornicroft, G., TAnsella, M., Becker, T., KNAPP, M., LeESE, M., SChene, A. et al. (2004). The personal impact of schizophrenia in Europe. Schizophr Res., 69, 125-132.

TIENARI, P., WYNNE, L. C., SORRI, A., LAHTI, I., LAKSY, K., MORING, J. et al. (2004). Genotypeenvironment interaction in schizophrenia-spectrum disorder. Long-term follow-up study of Finnish adoptees. Br.J Psychiatry, 184, 216-222.

TOsato, S., DAZzAn, P., \& COllier, D. (2005). Association between the neuregulin 1 gene and schizophrenia: a systematic review. Schizophr Bull, 31, 613-617.

Tunbridge, E. M., BAnnerman, D. M., Sharp, T., \& HARrison, P. J. (2004). Catechol-omethyltransferase inhibition improves set-shifting performance and elevates stimulated dopamine release in the rat prefrontal cortex. J.Neurosci., 24, 5331-5335.

Volkow, N. D., Gur, R. C., WAng, G. J., Fowler, J. S., MoberG, P. J., Ding, Y. S. et al. (1998). Association between decline in brain dopamine activity with age and cognitive and motor impairment in healthy individuals. Am J Psychiatry, 155, 344-349.

WEINBERGER, D. R. (1987). Implications of normal brain development for the pathogenesis of schizophrenia. Arch.Gen.Psychiatry, 44, 660-669.

WEINBERGER, D. R. (1999). Cell biology of the hippocampal formation in schizophrenia. Biol.Psychiatry, 45, 395-402.

WEINBERGER, D. R., BERMAN, K. F., \& CHASE, T. N. (1988). Mesocortical dopaminergic function and human cognition. Ann.N.Y.Acad.Sci., 537, 330-338.

Weinberger, D. R., EgAn, M. F., Bertolino, A., CAllicotT, J. H., Mattay, V. S., Lipska, B. K. et al. (2001). Prefrontal neurons and the genetics of schizophrenia. Biol.Psychiatry, $50,825-844$.

Westerink, B. H. C., De Boer, P., De Vries, J. B., Kruse, C. G., \& LONG, S. K. (1998). Antipsychotic drugs induce similar effects on the release of dopamine and noradrenaline in the medial prefrontal cortex of the rat brain. European Journal of Pharmacology, 361, 27-33.

WILliAMS, G. V. \& GOLDMAN-RAKIC, P. S. (1995). Modulation of memory fields by dopamine D1 receptors in prefrontal cortex. Nature, 376, 572-575. 
Wilson-Annan, J. C., Blackwood, D. H., Muir, W., Millar, J. K., \& PORTEOUs, D. J. (1997). An allelic association study of two polymorphic markers in close proximity to a balanced translocation t(1:11) that co-segregates with mental illness. Psychiatr.Genet, 7 , 171-174.

WISE, R. A. (1998). Drug-activation of brain reward pathways. Drug Alcohol Depend., 51, 13-22.

YAVich, L., Forsberg, M. M., KARAYiorgou, M., Gogos, J. A., \& MANnisto, P. T. (2007). Site-Specific Role of Catechol-O-Methyltransferase in Dopamine Overflow within Prefrontal Cortex and Dorsal Striatum. Journal of Neuroscience, 27, 10196-10209. 